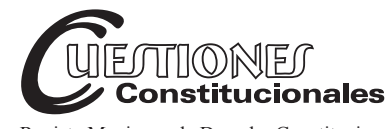

Revista Mexicana de Derecho Constitucional Núm. 43, julio-diciembre 2020

\title{
El derecho de identidad de personas transgénero en procedimientos de corrección de actas del registro civil. Una propuesta de sentencia estructural de la Suprema Corte de Justicia de la Nación
}

\author{
The right of identity for transgender people in procedures \\ for correcting civil registry records. A proposal for a structural \\ sentence of the Supreme Court of Justice of the Nation
}

\section{Jesús Manuel OrozCo PULIDO*}

RESUMEN: El derecho a la identidad es un derecho humano de suma importancia. Las personas de la comunidad trans han encontrado obstáculos para corregir sus documentos personales a fin de adecuarlos a la identidad de género que viven. La falta de normas jurídicas y el dictado de sentencias individuales de amparo han mostrado la insuficiente protección de los derechos de este grupo social, que usualmente padece discriminación. Esta investigación propone que la Suprema Corte mexicana, ejerciendo como tribunal constitucional, emita una sentencia estructural que haga visible la necesidad de regular el tema. A través de los contenidos constitucionales que actualmente están previstos en la Constitución mexicana, es posible emitir un fallo de esa naturaleza.

Palabras clave: derecho a la identidad, registro civil, personas transgénero, Suprema Corte de Justicia de la Nación, sentencias estructurales.
ABSTRACT: The right to personal identity is a crucial human right. In order to correct personal documents that fits with personal identity, transgender people have struggled. Lack of regulation and individual cases by judiciary, have shown that there are no sufficient means to protect rights of a community that has been discriminated. This research proposes that Mexican Supreme Court, acting as a constitutional court, issues a structural injunction in order to make visible the need to regulate this issue. Constitutional clauses that are already set on Mexican constitution are sufficient to issue the proposed resolution.

Keywords: right to personal identity, civil registers, transgender people, Mexican Supreme Court, structural injunctions.

* Maestro en derecho parlamentario y redacción normativa (LUISS Guido Carli, Universidad Complutense de Madrid y University of London). Fundador de la firma Orozco \& Pulido's Abogados. México. ORCID: 0000-0002-4691-1710 Contacto: orozco. jesusmanuel@gmail.com. 
SUMARIO: I. Introducción. II. Conceptos relacionados con la comunidad trans. III. Normativa en México. IV. Precedentes judiciales en México. V. Experiencia normativa y judicial en países extranjeros. VI. Hacia una sentencia estructural de la Suprema Corte de Justicia de la Nación. VII. Epílogo. VIII. Bibliografía.

\section{INTRODUCCIÓN}

Los derechos humanos están en el centro del debate jurídico del siglo XXI. En México, la reforma constitucional del 10 de junio de 2011 puso el acento sobre la importancia de tutelar más amplios niveles de protección a los derechos inherentes a la dignidad del ser humano, a fin de mejorar la calidad de vida de las personas. Basta mirar la décima época del Semanario Judicial de la Federación para advertir que las tesis de la Suprema Corte y tribunales federales tienen un eje argumentativo distinto. Se pasó de una pluralidad de criterios sobre fundamentación y motivación, seguridad jurídica o indefensión, hacia una doctrina constitucional, que desarrolla los derechos fundamentales y emplea técnicas de avanzada, como el juicio de proporcionalidad o la interpretación conforme.

Un derecho humano que aún está pendiente por explorar con más detalle es el derecho a la identidad. Somos personas en la medida en que desplegamos libremente nuestros rasgos identitarios, lo cual precisa el reconocimiento de terceros y del Estado para disfrutar plenamente los atributos de nuestra persona. Nombre, parentesco, sexo, edad, género y cultura son cuestiones que atañen al derecho a la identidad.

No confundir identidad con personalidad. La doctrina jurídica mexicana ha entendido la personalidad en términos de representación, cuando los actos que alguien efectúa como persona legitimada para actuar en nombre de otro. ${ }^{1}$ Por su parte, la identidad es un derecho fundamental que se reconoció constitucionalmente en la reforma publicada el 17 de junio de 2014, insertándolo en el artículo 4o., octavo párrafo.

En la fijación de los linderos de la identidad han intervenido asiduamente los tribunales, como en Italia o Argentina, donde los fallos de la jurisdic-

\footnotetext{
1 Soberón Mainero, Miguel, "Personalidad", Diccionario jurídico mexicano, México, t. VII, P-Reo, UNAM, 1984, p. 104. 
ción enmarcan específicas actividades de las personas como expresiones de su propia identidad. Por ejemplo, los caracteres físicos y morales, la profesión o eventos abstractos que expresan la cultura de cada pueblo se entienden como parte integral del derecho a la identidad. ${ }^{2}$

La identidad de género es un tema que poco ha sido explorado en la tradición jurídica mexicana. De inicio, existen pocas normas jurídicas que atienden el tema en cuanto a los procedimientos ante el registro civil para la reasignación de sexo. En la Gaceta Oficial del entonces Distrito Federal, el 10 de octubre de 2008, se incorporó en el Código Civil un mecanismo para la reasignación sexo genérica de personas trans. Empero, no existe regulación sobre matrimonio o adopción, de acceso a pensiones de viudez.

John Stuart Mill incorporó la idea de que el Estado tiene límites para entrar en la personalidad y cuerpo de una persona. ${ }^{3}$ Este sino libertario lleva a repensar las normas jurídicas y prácticas judiciales mexicanas que impiden a las personas transgénero el libre ejercicio de su derecho a la identidad. Indudablemente, es el reconocimiento que el Estado realiza hacia la identidad de género de cada persona el primer eslabón para ejercitar plenamente el resto de atributos jurídicos de la persona. La ausencia de regulación sobre la materia revela una intención del Estado mexicano para invisibilizar a un grupo social que padece discriminación. ${ }^{4}$ En la medida en que no se mira una situación de inseguridad jurídica que vulnera derechos humanos, se evitan también las miradas de lobbys políticos o la comunidad internacional.

De manera casuística existen casos aislados en que se concede el amparo a personas transgénero contra actos del registro civil, o resoluciones judiciales que omiten realizar procedimientos para rectificar sus actas del registro civil, a fin de que correspondan con su nueva identidad de género.

La fórmula de Otero impide que las sentencias de amparo surtan efectos favorecedores hacia terceras personas que no participaron en la litis de ese específico proceso. Sin embargo, hay técnicas del derecho procesal constitucional que permitirían que la Suprema Corte, ejerciendo como el tribunal constitucional mexicano, dicte una sentencia estructural que coadyuve

2 Cantoral Domínguez, Karla, "El derecho a la identidad del menor: el caso de México”, Revista Boliviana de Derecho, La Paz, núm. 20, 2015, pp. 56-75.

3 Mill, John Stuart, Sobre la libertad, trad. Pablo de Azcárate et al., México, Gernika, 1991.

4 Guilabert, Aurelien, "Identidad y salud Transerval", nota publicada en El Sol de México, 12 de agosto de 2019. 
a que personas transgénero accedan a la rectificación de sus documentos personales sin excesivas complicaciones.

Cuando los derechos fundamentales se ejercen, emergen dinámicas estatales y privadas problemáticas. En relaciones inter partes hay derechos antagónicos, que, al colisionar, uno cede ante el otro. En relaciones con el aparato estatal, el derecho humano encuentra mermadas sus posibilidades por legislación restrictiva, lagunas o antimonias legales, o prácticas estatales que vulneran flagrantemente el contenido del derecho.

Lamentablemente, los escollos para ejercitar los derechos fundamentales son más graves cuando se ejercen por miembros de comunidades minoritarias o que son estructuralmente discriminadas. Las personas transexuales encuentran serios problemas jurídicos para dar el primer paso hacia su libre determinación de identidad de género, que es el reconocimiento del Estado en sus actas de nacimiento y en sus documentos personales. Cuando el género que voluntariamente ejercen no se corresponde con el sexo bilógico que consta en sus documentos, es menester rectificarlo. Empero, cuando los órganos del Estado traban ese camino, por falta de legislación o prácticas administrativas que lo impiden, debe imponerse un remedio en aras de la eficacia de los derechos humanos.

\section{CONCEPTOS RELACIONADOS CON LA COMUNIDAD TRANS}

El sexo de una persona se determina por un binarismo fisiológico, que es identificado desde los ultrasonidos pélvicos durante la gestación. Para definir el sexo han de considerarse las diferencias biológicas entre el hombre y la mujer, diferencias que generan características genéticas, hormonales, anatómicas y fisiológicas sobre cuya base una persona es clasificada al nacer como hombre o mujer. ${ }^{5}$

En concreto, los genitales de la persona determinan si es hombre o mujer, y a partir de ahí se determina el entorno social que determina su personalidad con base en el sexo que le corresponde. Es de considerarse que existen teorías disruptivas que critican el binarismo del sexo, pues también existen personas intersexuales que la anatomía sexual de la persona no se ajusta físicamente a los estándares culturalmente definidos para el

5 Corte Interamericana de Derechos Humanos, Opinión Consultiva OC-24/17, del 24 de noviembre de 2017, solicitada por la República de Costa Rica, Identidad de género e igualdad y no discriminación a parejas del mismo sexo. 
cuerpo femenino o masculino. ${ }^{6}$ Inclusive, los componentes del sexo han sido disgregados para analizarlos desde el punto de vista cromosómico, morfológico, hormonal, psicológico o social, ${ }^{7}$ lo que revela que el término no es de fácil identificación.

En cambio, el concepto género adquiere más complejidad, porque se refiere a las identidades, funciones y atributos construidos socialmente de la mujer y el hombre, y al significado social y cultural que se atribuye a esas diferencias biológicas. ${ }^{8}$ En otras palabras, el género se refiere a la construcción de un comportamiento que se determina por los patrones del comportamiento de una persona. ${ }^{9}$

En el caso de personas transgénero, existe una diferencia bien definida entre su sexo biológico y la propia identidad de género que ejerce. Cuando el sexo biológico de una persona no se corresponde con los patrones psicosociales que siente o vive, se considera que es una persona trans.

Hablar de la comunidad trans implica referirse a un concepto sombrilla que recibe dentro de él a una pluralidad de expresiones de la diversidad sexual. Independientemente de un tratamiento médico o intervenciones quirúrgicas, el común denominador es la no conformidad entre el sexo asignado al nacer de la persona y la identidad de género que ha sido tradicionalmente asignada a éste. Una persona transgénero o trans puede identificarse con los conceptos de hombre, mujer, hombre trans, mujer trans y persona no binaria, o bien con otros términos como hijra, tercer género, biespiritual, travesti, fa'afafine, queer, transpinoy, muxé, waria y meti. ${ }^{10}$

La gran variedad de vivencias internas de la comunidad trans revela la complejidad del tema y cómo ha sido disruptivo de la tradicional concepción binaria de hombre y mujer. La cultura queer nacida en la década de los ochenta hace énfasis en deconstruir conceptos tradicionales de la cultura y del derecho mediante posturas del transgenerismo. ${ }^{11}$

6 Elósegui Itxaso, María, “El TJCE y el matrimonio de transexuales. Una interpretación «Ultra vires»”, Unión Europea Aranzadi, España, núm. 5, 2004, pp. 13-24.

7 Gerry-Vernières, Stéphane, "Droit à la vie privée et familiale. Le soft law dans le domaine des droits fondamentaux", Revue trimestrielle des droits de l'homme, Paris, núm. 110, 2017, pp. 307-349.

8 Corte Interamericana de Derechos Humanos, Opinión consultiva OC-24/17, op. cit.

9 De Montalvo Jääskeläinen, Federico, "Problemas legales acerca del tratamiento médico de la disforia de género en menores transexuales", Revista General de Derecho Constitucional, Madrid, núm. 24, 2017.

10 Corte Interamericana de Derechos Humanos, Opinión consultiva OC-24/17, op . cit.

11 Elósegui Itxaso, María, "El TJCE y el matrimonio de transexuales...", op. cit. 
Hacia 1912, en Berlín, Alemania, se realizó la primera cirugía de cambio de sexo en el mundo, ${ }^{12}$ y en 1970 ocurrió lo propio en el Hospital General de la Ciudad de México. ${ }^{13}$ Una expresión mexicana de transexualismo está arraigada en la comunidad zapoteca de Juchitán, Oaxaca, con los muxe. Se trata de una persona que nace sexuado hombre, pero que en el transcurso de su vida se reconoce a sí mismo como distinto a los hombres y a las mujeres, el llamado tercer género indígena. ${ }^{14}$ La cuestión central es resaltar la autonomía de la persona para tomar decisiones en su vida con la correlativa protección del aparato estatal. ${ }^{15}$

Al margen de posiciones ideológicas, religiosas o de moralidad pública, el debate debe centrarse en una cuestión de derechos. Las personas que vivifican una identidad de género que difiere con su sexo biológico deberían tener vías jurídicas libres para ejercer sus derechos fundamentales en un plano de igualdad y libertad.

Tan no estamos acostumbrados a lidiar con el fenómeno del transexualismo, que hay problemas en la alusión a la persona promovente de acciones administrativas o judiciales para la reasignación de género, plantea dificultades. El español es una lengua que distingue los géneros, y el masculino agrupa también al femenino. Cuando se empleen sustantivos con acepciones de género al referirse a personas trans, es conveniente usar el término que corresponda con la identidad de género que siente, y no al sexo original. Esto ha planteado problemas, porque en el amparo directo 6/2018, que se analizará más adelante, la Suprema Corte reiteradamente hizo alusión a "el quejoso", cuando quien promovía era una persona con identidad de género femenino. Ni qué decir del uso corriente del lenguaje hacia personas trans en México. Recientemente trascendió en los medios

12 De Montalvo Jääskeläinen, Federico, "Problemas legales acerca del tratamiento médico...", cit.

13 Consejo para Prevenir y Eliminar la Discriminación de la Ciudad de México, Población LGBTTTI, actualización mayo 2018, disponible en: https://copred.cdmx.gob.mx/ storage/app/uploads/public/5b1/ff9/f94/5b1ff9f945326665643161.pdf, el 14-08-2019, 12:06 hrs.

14 Urbiola Solís, Alejandra et al., "Expresión y trabajo de los muxe' del istmo de Tehuantepec, en Juchitán de Zaragoza, México", Nova Scientia, Revista de Investigación de la Universidad de la Salle Bajío, León, México, vol. 9, núm. 19, 2017, pp. 502-527.

15 Monereo Atienza, Cristina, Diversidad de género, minorías sexuales y teorías feministas: superposiciones entre las teorías de lesbianas, gays, bisexuales y transexuales y el feminismo en la reformulación de conceptos y estrategias político-jurídicas, Madrid, Dykinson-Universidad Carlos III, Instituto de Derechos Humanos, 2015, p. 81. 
el caso de una mujer transgénero a quien el barista de una cafetería escribió un nombre masculino en su bebida, a pesar de que la cliente trans tiene aspecto de mujer y expresamente le manifestó su nombre en femenino. ${ }^{16}$

En suma, el libre desarrollo de la personalidad se proyecta sobre la imagen y se desarrolla dentro de un ámbito de privacidad, sin invasiones ni injerencias ilegítimas. ${ }^{17}$ Sin embargo, el derecho no ha respondido a cabalidad con el problema, de ahí la pertenencia de reflexionar en vías jurídicas para cristalizar el derecho a la identidad de personas trans.

\section{NORMATIVA EN MÉXICO}

Históricamente, los actos del registro civil pertenecían al dominio de la Iglesia católica. El nacimiento, bautismo, matrimonio o defunción de las personas estuvieron a cargo del clero hasta las leyes de reforma impulsadas por el presidente Benito Juárez. Particularmente la Ley Ocampo fijó la separación de la Iglesia en los actos del registro civil, al establecer la titularidad del Estado para los actos del registro civil. ${ }^{18}$

Es importante destacar el texto original de la Constitución mexicana de 1917 (artículo 130, párrafo tercero) que establecía que los actos del registro civil son de exclusiva competencia de los funcionarios y autoridades del orden civil en los términos prevenidos por las leyes. La actual redacción de esa cláusula constitucional está en el penúltimo párrafo del artículo 130, que prevé que los actos del estado civil son de la exclusiva competencia de las autoridades administrativas en los términos que establezcan las leyes.

Dos aspectos saltan a la vista: la competencia de las autoridades administrativas, que no judiciales, para desempeñar el registro civil, y el principio de reserva de ley, por cuanto el tema debe regularse en una norma jurídica con rango formal y material de ley. Asimismo, al no estar previsto el registro civil como un ámbito competencia exclusivo del Congreso fe-

\footnotetext{
16 Dina, Eduardo y Espejel, Citlalli, "Si ahora soy Ofelio, soy el más bonito que existe", El Universal, 11 de agosto de 2019.

17 Sentencia del 22 de junio de 2009 de la Sala Primera del Tribunal Superior de Justicia de la Comunidad de Madrid (La Ley 7261, del 14 de octubre de 2009). Estimación de la demanda de rectificación registral de nombre y sexo formulada por un varón que no se ha sometido a cirugía de reasignación de sexo (La Ley 9917/2009).

18 Torres López, Erasmo Enrique, "El registro civil en el norte de México", El Diario de Coahuila, 1 de agosto de 2019.
} 
deral, por la cláusula residual del artículo 124 constitucional, las entidades federativas han asumido las atribuciones del registro civil.

También existe una cláusula constitucional que, como expresión del federalismo, dota de validez a los actos del registro civil de una entidad federativa para que sean válidos en todo el país (artículo 121, fracción IV). Esta vía ha permitido articular un sistema de prevalencia de los derechos relacionados con la diversidad sexual. La Ciudad de México ha sido pionera en regular la libertad de las personas para establecer su proyecto de vida, y en el aspecto de matrimonio entre personas de mismo sexo o transexualidad ha emitido legislación señera. Esto ha permitido que cualquier mexicano, aun sin residir en la capital del país, acuda a la Ciudad de México a ejercer los actos de la diversidad sexual que ahí están legislados. Luego, por la cláusula de validez federal, esos actos jurídicos adquieren fuerza en su lugar de residencia.

La institución del registro civil permite al Estado, controlar aspectos elementales de las personas, tales como el nacimiento, parentesco, reconocimiento, adopción, matrimonio, divorcio o defunción. A esto se debe considerar la complejidad propia de enlazar la información de treinta y dos direcciones estatales del registro civil, una por cada entidad federativa, a fin de que los datos sean homogéneos, no se crucen, ni se disipen.

En 1997 se plasmó la aspiración del gobierno federal para que los registros civiles de las entidades federativas unifiquen sus procedimientos, dentro de un plan mayor encaminado a implementar una cédula nacional de ciudadanía. ${ }^{19} \mathrm{Al}$ día de hoy no se ha cristalizado esa aspiración, y el programa continúa siendo una asignatura pendiente.

La identificación de las personas en México muestra complejidades debido a la falta de un documento idóneo, gratuito y seguro para acreditar la existencia de las personas habitantes del territorio mexicano. Usualmente una persona mayor de edad utiliza la credencial para votar, emitida por la autoridad electoral, que contiene los datos personales de nombre, domicilio, edad, sexo, estado y fotografía de quien posee la credencial. Este documento es elaborado y gestionado por un organismo constitucional autónomo como el Instituto Nacional Electoral, cuya vocación es la organización del sistema electoral. Sin duda, la ratio de esta autoridad no es la administración del repositorio de identidad de los ciudadanos mexicanos.

\footnotetext{
19 Acuerdo sobre el programa de establecimiento del registro nacional de ciudadanos y la expedición de la cédula de identidad ciudadana, Diario Oficial de la Federación, 30 de junio de 1997.
} 
La falta de una cédula de identidad ciudadana genera problemas para conocer los datos personales de una persona, censar el número de ciudadanos, identificar a los menores de edad y establecer avances tecnológicos para la identificación plena de una persona - como el registro del iris o de huellas digitales - que evite el robo de identidad.

El derecho positivo prevé la existencia de una cédula de identidad ciudadana, pero se trata de letra muerta. La Ley General de Población (artículos 97 y 111), la Ley de Migración (artículo 36, fracción II) y el Acuerdo sobre el programa de establecimiento del registro nacional de ciudadanos y la expedición de la cédula de identidad ciudadana, ${ }^{20}$ se refieren al deber jurídico de tener un documento único de identificación.

El citado Acuerdo, en su punto 1.3.1, establece que el registro civil es la fuente más importante de información para establecer el registro nacional de ciudadanos, y propone que se legisle sobre la variedad de conceptos en las codificaciones civiles de las entidades federativas. Un especial énfasis se pone en los excesivos trámites para los registros extemporáneos de nacimiento, multiplicidad de criterios y procedimientos para asentar anotaciones marginales, disparidad de criterios y procedimientos para la aclaración y rectificación de actas del estado civil de las personas.

Sin duda, las mismas deficiencias del registro civil no han sido corregidas después de dos décadas, pues la regulación del registro civil continúa estando pendiente. Además, actualmente ha emergido una problemática que trasciende al derecho administrativo en cuanto a sus prácticas o procedimientos. La obstaculización para que personas transgénero accedan plenamente al ejercicio de su identidad de género y corrijan sus actas de nacimiento es un tópico que cae en el ámbito del derecho fundamental a la identidad, y en la contracara se encuentra un régimen de prácticas estatales que limitan el derecho de un grupo social discriminado.

Un instrumento, quizá el único, para la identificación global de los mexicanos es la CURP (clave única de registro de población), cuya expedición está a cargo de la Secretaría de Gobernación federal. ${ }^{21}$ Se trata de una secuencia alfanumérica de dieciocho caracteres que se asigna de forma individual a mexicanos y extranjeros residentes. La manera en que se compone está determinada por las letras iniciales de los apellidos y

\footnotetext{
20 Idem.

21 Instructivo normativo para la asignación de la Clave Única de Registro de Población, Diario Oficial de la Federación, 18 de junio de 2018.
} 
nombres; seis números, correspondientes a dos dígitos por el año, mes y día de nacimiento; la letra del sexo, $\mathrm{H}$ para hombre y M para mujer; la entidad federativa de nacimiento, y una secuencia de números individuales.

En caso de que una persona trans efectúe su reasignación de género, necesariamente habrá un escollo en el cambio de las iniciales del nombre de pila y la letra del sexo. Por una parte, no se prevén procedimientos para que la CURP sea modificada, y de hacerlo no quedaría registro alguno en poder del gobierno federal — salvo los registros propios del registro civil o del expediente judicial abierto al efecto, que por cierto no están debidamente articulados con los repositorios de consulta del Estado- para cohonestar la primera identidad de la persona trans con la clave poblacional en que conste el nuevo sexo.

Si la CURP no se modifica, se dejan datos que permitirían identificar la anterior identidad de la persona trans, pues en cualquier trámite que presente la clave fácilmente se detecta que las iniciales del nombre y la letra del sexo no se corresponden con la identidad que ejerce la persona.

Como se verá más adelante, el sigilo y secrecía absoluta en la reasignación de género de personas es un principio que debe cumplirse. Inclusive, el Pleno de la Suprema Corte otorgó un amparo para evitar que la anotación marginal en el acta de nacimiento de una persona trans deje entrever en cualquier acto futuro la reasignación sexo genérica. ${ }^{22}$

Esta diferencia hace notoria la necesidad de articular un modelo en que el Estado no pierda el control absoluto sobre la identificación de las personas, para mantener la identidad de las personas en los registros estatales. Inclusive, un voto particular del ministro Silva Meza razonó sobre la necesidad de que el Estado no pierda ese control a través de la anotación marginal levantada en las actas de nacimiento primigenia de personas trans que han modificado su identidad de género. ${ }^{23}$ La anotación marginal debiera surtir efectos para que la autoridad conozca, con absoluta reserva, las identidades de los habitantes; si bien la propia anotación es reservada ante terceros.

En la práctica, cuando una persona trans desea modificar su acta de nacimiento, y después el resto de documentos personales, tiene dos vías. El ordenamiento jurídico civil, tanto el federal como el particular de cada

22 Sentencia del Pleno de la Suprema Corte de Justicia de la Nación, amparo directo 6/2008, 6 de enero de 2009.

23 Voto particular del ministro Juan N. Silva Meza, contra la sentencia del Pleno de la Suprema Corte de Justicia de la Nación, amparo directo 6/2008, cit. 
entidad federativa, disponen estos dos mecanismos para la rectificación de actas del registro civil. La primera es la vía administrativa ante el propio registro civil, para modificar errores simples, como errores mecanográficos o de transcripción de documentos. La segunda es la vía jurisdiccional ante los jueces, para modificar aspectos esenciales, como la modificación de un nombre que cause afrenta a la persona o cambios en sus ascendientes tras reconocimientos de paternidad.

La persona que reasigna su sexo modifica dos cosas: su nombre, para hacerlo coincidir con un nombre que se ajuste a la identidad femenina o masculina que ejerce, y el sexo, para que corresponda con su identidad de género. Ciertamente, el cambio de nombre y sexo puede considerarse como una modificación esencial que amerita la intervención de un juez para dotar de seguridad jurídica el procedimiento; pero la tendencia normativa es simplificar y facilitar la reasignación de género a través de un procedimiento administrativo.

La producción normativa en el siglo XXI ha alcanzado niveles estratosféricos, que hacen ardua la labor de identificación de los contenidos que el operador jurídico necesita utilizar. En sistemas jurídicos del common law, que también tienen normas jurídicas positivas a pesar de que el precedente judicial es preponderante, se lleva a cabo una consolidación normativa para agrupar las regulaciones. ${ }^{24}$ En países de tradición civil, los códigos refundidos son un intento por volver a organizar la pluralidad de normas que han sido aprobadas. El código fue el instrumento normativo protagonista del siglo XX, pero actualmente ha sido desplazado por un alud de normas especiales, generales, marco o regulatorias, muchas de ellas con mala calidad técnica desde el punto de vista del legislative drafting. ${ }^{25}$

La realidad ha rebasado a las normas jurídicas, pues los cada vez más comunes procedimientos de reasignación de sexo ponen de manifiesto que la normativa es insuficiente para satisfacer el reclamo de igualdad y libertad de una comunidad minoritaria. Podría pensarse que, otra vez, es necesario una reforma constitucional ad hoc para generar una ley federal en materia de reasignación de género de personas transexuales. $\mathrm{O}$ entrando más en las prácticas mexicanas del constituyente permanente, dejar en un artículo transitorio la buena voluntad de emitir futuras normas en ese tema.

24 Samuel, Alec, “Consolidation: A plea", Statute Law Review, Oxford, vol. 59, 2005, p. 26.

25 Pizzorusso, Alessandro, "Recientes tendencias del parlamentarismo", Revista Vasca de Administración Pública, Bilbao, núm. 39, 1994, pp. 105-125. 
Parece más adecuado cesar con la sangría interminable de reformas constitucionales que han hecho que la ley suprema mexicana sea una Constitución de supuestos y especificidades, una Constitución atrapatodo. Los 239 decretos de reforma constitucional - que implican 732 modificaciones, actualizado hasta el 10 de agosto de $2019 £^{26}$ son elocuentes para mostrar que la intención contemporánea de México es crear derecho positivo a partir de cláusulas constitucionales, en lugar de desarrollar normas mediante el completo y complejo alud de principios que ya se tienen.

Inclusive, la Constitución federal ha impuesto al Congreso de la Unión la obligación de expedir leyes generales que armonicen y homologuen la organización y el funcionamiento de los registros civiles (artículo 73, fracción XXIX-R). Esta reforma se publicó el 5 de febrero de 2017, y entre los ámbitos que deben regularse aparecen los mecanismos de atención de grupos en situación de especial vulnerabilidad y marginación, y la simplificación de procedimientos de corrección, rectificación y aclaración de actas.

Hay otras cláusulas constitucionales que inciden en la identidad de personas trans, como el principio de progresividad (artículo 1o., tercer párrafo), el derecho a la igualdad (artículo 4o., octavo párrafo), la prohibición de todo acto de discriminación (artículo 1o., último párrafo), el derecho a la identidad (artículo 4, primer párrafo), los principios de competencia administrativa y reserva de ley que rigen al registro civil (artículo 130, penúltimo párrafo) y el mandato al Congreso de la Unión para armonizar y homologar los registros civiles (artículo 73, fracción XXIX-R). Como se ve, existe un andamiaje suficiente para crear una sentencia estructural.

Sin duda, existen suficientes insumos constitucionales para reconocer y desarrollar la identidad de género que asumen las personas trans, y en consecuencia movilizar la labor de diversas autoridades del Estado mexicano.

Los contenidos específicos de esa ley general deberían atender la cuestión del derecho de identidad de género de personas trans. Mientras eso ocurre, la Suprema Corte puede, mediante una sentencia estructural, movilizar el material constitucional que ya se tiene a fin de propiciar una regulación que tenga un piso mínimo de derechos para este grupo social.

26 Datos extraídos de la base de datos de la Cámara de Diputados del Congreso de la Unión, disponible en: $h t t p: / / w w w . d i p u t a d o s . g o b . m x / L e y e s B i b l i o / i n d e x . h t m$, consultado el 13-08-2019, a las 12:00 hrs. También se toma en cuenta el conteo de Fix-Fierro, Héctor et al., Constitución política de los Estados Unidos Mexicanos. Texto reordenado y consolidado, México, UNAM, 2016, p. 2. 


\section{Precedentes Judiciales en MÉXiCO}

La Suprema Corte ha resuelto casos relacionados con la rectificación de actas de nacimiento de personas trans que han decidido ejercer su derecho a la identidad de género, ya sea mediante la prosecución de juicios que ulteriormente llegan a la Corte mediante el amparo directo, o a través del planteamiento de inconstitucionalidad de códigos civiles que limitan la rectificación de actas de nacimiento, que llega a la Corte mediante el amparo en revisión.

En 2009, el Pleno resolvió el amparo directo $6 / 2008,{ }^{27}$ un caso donde una persona transexual promovió un juicio civil para rectificar su acta de nacimiento, y los órganos judiciales resolvieron que solamente procedía la modificación del nombre - cambiando un nombre masculino por uno femenino-, pero no así el sexo; además que el cambio debía plasmarse en una nota al margen levantada en su acta de nacimiento. El Pleno analizó un precepto del Código Civil del entonces Distrito Federal, que preveía la imposición de una nota marginal en el acta del registro civil que ha sido rectificada. El mismo precepto, con matices, está previsto en las normas de los estados que regulan la rectificación de los asientos del registro civil, normalmente el código civil o la ley del registro civil.

Una apretada mayoría de seis votos estableció que el precepto que regula la anotación marginal es apegado a la Constitución, pues permite dar seguimiento a la identidad de las personas, y así evitar trasgresiones al orden público y fraudes a terceros. El eje argumentativo giró sobre la interacción del derecho de identidad de género y los actos administrativos de registro civil, pues al mismo tiempo la reasignación sexogenérica se mantiene en un ámbito de privacidad, prohibiéndose la publicidad hacia terceros, como de control estatal, para evitar perder el registro de la identidad de los ciudadanos.

La mayoría en el Pleno zanjó el planteamiento de inconstitucionalidad mediante un tecnicismo muy fino: no se declara inconstitucional el precepto que regula la anotación marginal, toda vez que durante el trámite del juicio de amparo se reformó el sistema normativo civil para establecer una reforma que autoriza el procedimiento de reasignación sexogenérica. Así, el Pleno exigió a los tribunales ordinarios que realizaran una inter-

27 Sentencia del Pleno de la Suprema Corte de Justicia de la Nación, amparo directo 6/2008, cit. 
pretación integradora del ordenamiento civil a efecto de incorporar a sus resoluciones los lineamientos de la nueva normativa.

Asimismo, la sentencia estableció que los actos realizados por una persona transexual bajo su anterior identidad, que generaran o pudieran generar obligaciones o responsabilidades al individuo, le serán exigibles en los términos de las leyes aplicables. De igual manera, sus derechos tampoco se extinguen por la reasignación de sexo, tales como los derechos de sucesión, contratos civiles, o antigüedad en el trabajo. Sin duda, esta reflexión debiera llevarse a una legislación sobre la materia, que articule la manera en que los derechos y obligaciones adquiridos por la persona trans no desaparecen por su reasignación de género.

Tiene particular relevancia el voto particular del ministro Silva Meza, ${ }^{28}$ quien afirmó que la anotación marginal sí debe subsistir, pero sólo para que la autoridad ejecute un control absoluto del historial de cada individuo; en cambio, la anotación marginal desaparece para los particulares, toda vez que debe expedirse una nueva acta de la persona trasgénero, sin mención alguna sobre el cambio y sin permitir la publicidad a terceros.

Años después, ya durante la décima época, la Primera Sala resolvió el amparo en revisión 1317/2017. ${ }^{29}$ La materia de estudio versó sobre un control concentrado de constitucionalidad del sistema normativo civil del estado de Veracruz, que distingue entre una vía administrativa y una vía judicial para realizar las modificaciones a las actas del registro civil. El asunto trae cuenta de una persona trans que ante el registro civil solicitó la rectificación de su acta de nacimiento para adecuarla a su género. $\mathrm{Su}$ petición se desestimó aduciendo que ese tipo de rectificaciones deben tramitarse por la vía judicial y no ante el registro civil.

Esto permitió a la Primera Sala, fijar qué vía procedimental — la administrativa ante el registro civil, o la jurisdiccional ante un juez- es la más idónea para que la persona transgénero promueva la modificación de su acta de nacimiento. La manera de construir la sentencia fue peculiar. Se tomó como referencia que en el estado de Veracruz el acto jurídico de reconocimiento de un padre a un hijo es posible realizarlo en sede administrativa ante el oficial del registro civil. El acta de reconocimiento, sin duda, modifica el apellido y parentesco del menor, con lo cual se trata de una modificación esencial en la identidad del reconocido. El mismo efecto

\footnotetext{
28 Op. cit.
}

29 Primera Sala de la Suprema Corte de Justicia de la Nación, sentencia dictada en el amparo en revisión 1317/2017, 17 de octubre de 2018. 
de modificación esencial acontece con el levantamiento de una nueva acta de nacimiento con motivo de la reasignación de género, toda vez que hay cambios en el nombre y sexo del registrado.

A la luz del derecho a la igualdad, existe un trato legal diferenciado y desproporcional, toda vez que por una parte se autoriza que, por ejemplo, el reconocimiento se efectúe ante el registro civil, pero la reasignación de género se reconduce a una vía jurisdiccional. Este sistema normativo no superó el test de proporcionalidad y fue declarado inconstitucional por la Primera Sala.

Esta sentencia reproduce totalmente las consideraciones de la Corte Interamericana de Derechos Humanos en la Opinión consultiva 24/17. El tribunal interamericano estableció un marco referencial de cinco requisitos, que deben cubrirse en los procedimientos del registro civil encaminados a la reasignación de sexo en casos de personas transexuales, a saber: i) un procedimiento que sea adecuado e integral; ii) el consentimiento libre e informado de la persona transexual; iii) que el procedimiento sea confidencial; iv) que sea expedito y tienda a la gratuidad, y v) que no se exija acreditar operaciones o tratamientos médicos para la reasignación de sexo.

El mismo catálogo de requisitos fue reiterado por la Primera Sala, que si bien no estaba obligada a aplicar la opinión consultiva, tuvo el mérito de incorporar al sistema jurídico nacional, por la vía del soft law, estándares internacionales de apreciación, interpretación y validez en un tema técnico y políticamente sensible.

Respecto a la calidad del procedimiento adecuado e integral, en el párrafo 124 de la citada opinión consultiva, la Corte Interamericana estableció que basta con la rectificación ante el registro civil para que se evite una pluralidad de trámites de la persona trans, a fin de evitar un trámite por cada documento personal que se desee corregir. Se reconoció la libertad configurativa de cada Estado parte, pero en el párrafo 159 se fijó que el procedimiento que mejor se ajusta es de índole administrativa. Esto fue retomado por la Primera Sala, y se concluyó que el procedimiento más idóneo para la reasignación sexogénerica es la vía administrativa, a fin de evitar las excesivas demoras y costos de una vía jurisdiccional.

Pasó desapercibido para la Suprema Corte, que una clave argumentativa que hubiera reforzado enormemente la sentencia es el artículo 130, penúltimo párrafo, de la Constitución federal, que establece la competencia de las autoridades administrativas, y no judiciales, para conducir los actos del registro civil. 
En otro aspecto, las resoluciones judiciales en México sobre el tema también han provenido de tribunales colegiados de circuito, que fungen como órganos terminales en materia de legalidad y dotan al sistema jurídico nacional de interpretaciones cotidianamente aplicadas en todo el país. En la competencia de los tribunales colegiados hay interpretaciones yuxtapuestas. Se trata de un claro ejemplo en que una laguna legislativa tampoco ha sido aclarada pacíficamente por la jurisprudencia.

Respecto a un tópico tan elemental como la vía procesal para llevar a cabo la reasignación de sexo, hay un tratamiento judicial disímil, según la entidad federativa en que se plantee. Por una parte, el Pleno del decimoséptimo circuito estableció en una contradicción de tesis - es decir, hubo criterios divergentes dentro del propio circuito - que la legislación de Chihuahua sobre rectificación de actas del registro civil debe interpretarse en el sentido de que la vía administrativa es la más congruente para tutelar el derecho de identidad de género. ${ }^{30}$ Este criterio tiene efectos vinculantes, y debe ser cumplido (artículo 217, párrafo tercero, de la Ley de Amparo), y por lo menos la práctica demuestra que los órganos judiciales del fuero común dialogan con más asiduidad con los criterios de sus propios circuitos que con la Suprema Corte.

Por el contrario, un tribunal colegiado de Guanajuato estableció una jurisprudencia por reiteración —es decir, el mismo criterio reiterado en cinco sentencias - respecto a que el establecimiento de una vía jurisdiccional para la rectificación de actas de reasignación de sexo supera el test de proporcionalidad y no lesiona derechos fundamentales. ${ }^{31}$

La diferencia es notoria: en el estado de Chihuahua se ha interpretado que la vía administrativa, es decir, ante el propio registro civil, es indis-

30 Pleno del Decimoséptimo Circuito, sentencia en la contradicción de tesis 6/2018, del 9 de abril de 2019. De esta contradicción de tesis surgió la jurisprudencia PC.XVII. J/20 A (10a.), Gaceta del Semanario Judicial de la Federación, Décima Época, libro 67, junio de 2019, tomo V, p. 4274, de rubro: "Identidad de género auto-percibida. Los artículos 48, 130 y 131 ter del Código Civil del Estado de Chihuahua, transgreden los derechos a la igualdad, a la identidad y al nombre de las personas transgénero, al contener una discriminación normativa".

31 Primer Tribunal Colegiado en Materia Administrativa del Décimo Sexto Circuito, jurisprudencia XVI.1o.A. J/47 (10a.), Gaceta del Semanario Judicial de la Federación, Décima Época, libro 56, julio de 2018, tomo II, p. 1421, de rubro: "Reasignación sexogenérica. El establecimiento de un procedimiento jurisdiccional para modificar las actas de nacimiento, a efecto de hacerla constar, supera el test de proporcionalidad en sentido estricto (legislación del Estado de Guanajuato)". 
pensable para tutelar el derecho de identidad de género; mientras que en el estado de Guanajuato se han decantado por la vía jurisdiccional. Ciertamente, la jurisprudencia de Chihuahua es compatible con el criterio de la Primera Sala en el amparo en revisión 1317/2017, pero el criterio de Guanajuato aún no ha sido superado mediante una contradicción de tesis.

Por su parte, en el estado de Jalisco un tribunal colegiado estableció que la omisión de expedir una nueva acta de nacimiento a la persona que ha reasignado su sexo es violatoria de derechos fundamentales. ${ }^{32}$ De nueva cuenta, se corrigió la práctica del registro civil local en no reexpedir una nueva acta de nacimiento para la persona trans, que esté incólume de datos que revelen su anterior condición sexual.

La legislación del estado de Veracruz se declaró inconstitucional por la Primera Sala en el amparo en revisión 1317/2017. Mientras que en el amparo directo 6/2008 el Pleno declaró constitucional la anotación marginal regulada en el entonces Distrito Federal, cuya ratio normativa aparece en todas las codificaciones del país.

Otro aspecto relevante es que en juicios de amparo promovidos por personas trans surgió una contradicción de tesis para dilucidar la especialidad que deben tener los órganos jurisdiccionales que conozcan juicios de amparo interpuestos contra actos u omisiones del registro civil. La jurisprudencia 1a./J. 36/2019 (10a.) de la Primera Sala estableció que si bien el registro civil es una autoridad administrativa, pues orgánicamente depende del Poder Ejecutivo de las entidades federativas, lo cierto es que sus actos versan sobre el registro de las personas, cuyo contenido es de naturaleza civil. ${ }^{33}$ Así, la especialización de los órganos judiciales es de materia civil, y no administrativa.

32 Cuarto Tribunal Colegiado en Materia Civil del Tercer Circuito, sentencia en el amparo en revisión 153/2018, del 8 de junio de 2018. De esta sentencia surgió la tesis III.4o.C.45 C (10a.), Gaceta del Semanario Judicial de la Federación, Décima Época, libro 60, noviembre de 2018, tomo III, p. 2378, de rubro: "Reconocimiento de identidad de género. Las disposiciones del Código Civil y de la Ley del Registro Civil del Estado de Jalisco, al no prever la posibilidad de expedir un acta de nacimiento en la que se haga constar aquella situación, en ejercicio del control de convencionalidad, deben inaplicarse".

33 Tesis 1a./J. 36/2019 (10a.), Gaceta del Semanario Judicial de la Federación, Décima Época, libro 69, agosto de 2019, tomo II, p. 1045, de rubro: "Competencia para conocer del juicio de amparo indirecto cuando se impugnen actos u omisiones de las autoridades del registro civil relacionados con el estado civil de las personas. Corresponde al juez de distrito en materia civil, cuando se dé la especialización”. 
A los problemas de interpretación propios de cualquier tema jurídico novedoso se añade un problema endémico de México derivado de la ausencia de un sistema sólido de obligatoriedad de los precedentes dictados por la Suprema Corte. No es este el lugar para profundizar sobre las causas y efectos, ${ }^{34}$ pero baste decir que la vinculación de la jurisprudencia de la Suprema Corte está determinada por el tipo de asunto donde emite el fallo. Por ejemplo, si dicta sentencia en las acciones y controversias del artículo 105 constitucional o en contradicciones de tesis, se genera una jurisprudencia de observancia obligatoria; en cambio, si dicta una sentencia en cualquier otro proceso del amplio abanico competencial que tiene, solamente se origina una tesis aislada que jurídicamente no vincula.

Según la propia Suprema Corte, una tesis es la expresión por escrito, en forma abstracta, de un criterio jurídico establecido al resolver un caso concreto; no es un extracto, una síntesis o un resumen de la sentencia. ${ }^{35} \mathrm{Si}$ no se publican tesis de una sentencia, prácticamente la doctrina constitucional pasa desapercibida para los operadores jurídicos. Esto provoca que, por ejemplo, las tesis aisladas emitidas en el amparo directo $6 / 2008$ y en el amparo en revisión 1317/2017 sean el único insumo que la Corte otorga al foro jurídico; y el resto de argumentos de la sentencia, así se trate de ratio decidendi, pasan desapercibidos.

El sistema de obligatoriedad todavía está pensado en términos de una corte de casación que unifica la jurisprudencia de los órganos inferiores, y no como un tribunal constitucional que tiene la última palabra en la interpretación de la Constitución, y sus sentencias vinculan y dialogan con todos los poderes del Estado.

Hay otro problema de enorme gravedad: la jurisprudencia no es obligatoria para autoridades del orden administrativo, siendo únicamente vinculante para aquellas que ejercen jurisdicción. ${ }^{36}$ En un ordenamiento en el que

34 Orozco Pulido, Jesús Manuel, "La Suprema Corte de Justica de México y su sistema de creación jurisprudencial: defectos y retos", en Cucarella, Luis (coord.), Derecho procesal convencional. El nuevo desafio de la justicia constitucional, Bogotá, Ediciones Nueva Jurídica, 2016, pp. 487-492.

35 Acuerdo General 20/2013, del 25 de noviembre de 2013, del Pleno de la Suprema Corte de Justicia de la Nación, relativo a las reglas para la elaboración, envío y publicación en el Semanario Judicial de la Federación y su Gaceta, de las tesis que emiten la Suprema Corte de Justicia, los Plenos de Circuito y los Tribunales Colegiados de Circuito.

36 Tesis 2a./J. 38/2002, Semanario Judicial de la Federación y su Gaceta, Novena Época, 186921, tomo XV, mayo de 2002, p. 175, de rubro: “JURISPRUDENCIA SOBRE IN- 
pululan los organismos autónomos que fungen como entes regulatorios o de control, amén de la pluralidad de autoridades administrativas del orden federal, estatal o municipal —incluidos aquí todos los oficiales del registro civil del país- es necesario repensar la conveniencia de que una sentencia de la Suprema Corte guíe el actuar de todas las autoridades nacionales.

Una sentencia del tribunal constitucional evita que una pluralidad de causas particulares se ralenticen en una cadena judicial que, después de años de cansado litigio, llegue a órganos terminales en que sí se aplique una jurisprudencia que desde el inicio hubiera superado el escollo.

La doctrina constitucional que ha emanado de los amparos resueltos por la Suprema Corte en materia de identidad de género de personas trans se ciñe a siete tesis aisladas del amparo directo 6/2008, y seis del amparo en revisión 1317/2017, mientras que los criterios emanados de Chihuahua y Guanajuato sí son jurisprudencia obligatoria, y técnicamente no puede existir una contradicción de tesis entre un pleno o tribunal colegiado de circuito y la Suprema Corte.

En la práctica, el operador jurídico adscribe un mayor valor a una tesis de la Suprema Corte que a una jurisprudencia de un tribunal colegiado de circuito. Sin embargo, no parece adecuado que haya diversidad de criterios en un tema sensible que incide en un derecho fundamental básico de un grupo social discriminado. Recordemos que la opinión consultiva 24/17 del tribunal interamericano hace énfasis en la celeridad y rapidez en los procedimientos de reasignación de género, por lo que las autoridades administrativas del registro civil debieran ceñirse a cualquier criterio jurisprudencial en que la Suprema Corte dé directrices a su actuar.

Es importante discutir sobre la obligatoriedad de la jurisprudencia del tribunal constitucional mexicano, particularmente hacia autoridades administrativas. Por ejemplo, como se verá en el apartado siguiente, la Corte Constitucional de Colombia ordenó a la superintendencia competente la emisión de una circular para que los notarios ajustaran sus procedimientos a la sentencia constitucional, respecto a la reasignación de género de una persona trans menor de edad.

La expeditez y prontitud en el establecimiento de los derechos de la persona transgénero es crucial. Hay efectos perniciosos en la vida cotidiana de una persona trans que, al no tener sus documentos personales que co-

CONSTITUCIONALIDAD DE LEYES. LAS AUTORIDADES ADMINISTRATIVAS NO ESTÁN OBLIGADAS A APLICARLA AL CUMPLIR CON LA GARANTÍA DE FUNDAR Y MOTIVAR SUS ACTOS”. 
rrespondan a su identidad, irrogan problemas para celebrar actos jurídicos tan elementales como inscribirse a una universidad, abrir una cuenta bancaria o celebrar contratos civiles y laborales. No es justo que una persona cotidianamente ejerza actos con documentos que no se corresponden con la identidad que libremente decide ejercer.

Esto conduce a repensar el rol que la Suprema Corte mexicana podría jugar en la eficacia y cumplimiento del derecho a la identidad de género en los actos del registro civil. Una vía pertinente para irradiar la interpretación protectora de derechos humanos de la comunidad trans, y dotar a la doctrina constitucional de la Corte con mayor eco y eficacia, es la emisión de una sentencia estructural que atienda el tema.

\section{EXPERIENCIA NORMATIVA Y JUDICIAL EN PAÍSES EXTRANJEROS}

Existen normas jurídicas y precedentes judiciales en América Latina y Europa que muestran que el camino por cristalizar derechos a miembros de la comunidad trans ha sido difícil, pero hay avances. ${ }^{37}$ Por vía de ejemplo, los avances en el derecho alemán han sido perfilados por sentencias del tribunal constitucional federal que han fijados estándares de protección a los derechos de la comunidad trans. ${ }^{38}$

Diversas normas jurídicas han señalado requisitos que, una vez anulados en la jurisdicción constitucional, han sido eliminados por el legislador. Tal ha sido el caso de la fijación de una edad mínima de veinticinco años para llevar a cabo la reasignación de género, el requerimiento de no estar casado para proceder a la nueva identidad, o exigir pruebas médicas que acrediten una incapacidad de reproducción y tratamientos médicos para la reasignación de género. ${ }^{39}$ El legislador libremente crea el derecho positivo

\footnotetext{
37 En las páginas 90 a 96 de la sentencia del Pleno de la Suprema Corte de Justicia de la Nación, en el amparo directo 6/2008, resuelto en sesión del 6 de enero de 2009, se citan una pluralidad de normas jurídicas y precedentes judiciales de Italia, Alemania, Reino Unido, Holanda, España, Argentina, Francia, Colombia, Perú y Chile.

38 Von Stritzky, Johannes, "El desarrollo de la protección jurídica de las personas homosexuales, bisexuales, transexuales e intersexuales (LGBT) en Alemania”, Revista General de Derecho Constitucional, España, núm. 17, 2013, p. 6.

39 Idem.
} 
con su margen de apreciación, pero la jurisdicción ha anulado normas que no respetan los cánones constitucionales.

Por su parte, en 2002 el Tribunal de Derechos Humanos de la Unión Europea se pronunció sobre el derecho de identidad de personas transexuales, en el caso Goodwin v. Reino Unido; mientras que el Tribunal de Justicia de la Unión Europea reconoció el derecho de matrimonio y de pensiones de viudedad a parejas transexuales, en el caso K.B. v. Reino Unido en 2004. ${ }^{40}$ El diálogo judicial europeo ha levantado críticas, aduciéndose que las cortes de justicia internacionales generan derechos sin tener en cuenta los procedimientos formales de creación de derecho positivo de los Estados miembros. ${ }^{41}$ Sin duda, se trata del debate perenne sobre activismo judicial, la maximización de derechos y la autorrestricción.

Respecto del derecho a la identidad de personas transexuales, la Corte Constitucional de Colombia ha establecido criterios innovadores y sagaces en acciones de tutela que reconocen a personas transexuales estándares de protección y reconocimiento a sus derechos. Tres sentencias merecen un comentario específico.

A pocos años de su establecimiento tras la Constitución de Colombia de 1991, la alta jurisdicción constitucional emitió la sentencia T-477/95 que otorga una tutela a quien siendo menor de edad fue sometido a tratamientos médicos para remodelar sus genitales, que aparentemente fueron cercenados por la mordedura de un perro. ${ }^{42}$ Sin tener el consentimiento pleno e informado del menor ni de sus padres, quienes carecían de instrucción dada su vida campesina, los médicos tratantes decidieron efectuar una meatotomía para paliar el cercenamiento de los genitales masculinos del niño. Seis años después, otra vez sin tener un consentimiento pleno e informado del paciente, efectuaron una cirugía de reasignación de sexo para que el paciente tuviera genitales femeninos. Pasados los años, en el paciente emergió su condición biológica masculina, manifestándose en sus rasgos fenotípicos, en su comportamiento social y psicológico y en su identidad de género. De esta manera, la vulneración en sus derechos se materializó, porque la reasignación de sexo no le fue consultada, lo que a la postre de-

\footnotetext{
40 Navarro Batista, Nicolás, "Los transexuales en la jurisprudencia europea: comentario al asunto K.B. (sentencia del TJCE de 7 de enero de 2004, as. C-117/01)", Revista General de Derecho Europeo, núm. 4, 2004.

41 Elósegui Itxaso, María, "El TJCE y el matrimonio de transexuales...", cit.

42 Sentencia de la Corte Constitucional de Colombia, T-477/95, 23 de octubre de 1995.
} 
rivó en un choque frontal entre su identidad de género y los genitales que médicamente le fueron confeccionados.

La sentencia inició citando a John Locke como fundamento de la libertad individual, que adquiere mayor relevancia en el cuerpo humano como expresión básica de las decisiones personales. Se fijó que el ser humano no es un juguete de experimentos médicos, por lo que en casos de procedimientos médicos para la reasignación sexogenérica debe tenerse en cuenta el consentimiento libre, informado y reforzado del paciente, que se extiende a sus padres cuando es menor de edad.

En 2017, la Corte Constitucional colombiana emitió sentencias de enorme valía para la comprensión de los derechos de personas transexuales. En la T-498/2017 se fijaron los parámetros que debe tener el consentimiento informado de un menor de edad transgénero para proceder a adecuar su identidad de género: i) la clara voluntad del menor y de sus padres; ii) la proximidad a la mayoría de edad; iii) los informes o tratamientos médicos; iv) la consideración de que la reasignación sexogenérica en sus documentos personales podría ser revertida. ${ }^{43}$ Este último requisito, tomando en cuenta que el decreto 1217 de 2015 del Ministerio de Justicia y del Derecho autoriza la corrección transcurridos diez años desde la emisión de la escritura de reasignación, y limita la corrección a dos ocasiones. ${ }^{44}$

Por su parte, la T-675/2017 versó sobre la negativa notarial en realizar el cambio en la partida de nacimiento en los apartados de nombres y sexo, a fin de readecuarlos a la identidad de género de un menor de edad..$^{45}$ El quid fue analizar el requisito de mayoría de edad del decreto 1217 de 2015 del Ministerio de Justicia y del Derecho, que prevé que la petición de reasignación de género debe realizarse por persona mayor de edad. El requisito de mayoría de edad, si bien expresamente no está previsto en el decreto, de forma implícita subyace por el deber de acompañar a la petición de reasignación de sexo la cédula de ciudadanía, que es un documento expedido solamente a los mayores de edad. Mutatis mutandis, igual escenario acontecería en

\footnotetext{
43 Sentencia de la Corte Constitucional de Colombia, T-498/17, 3 de agosto de 2017.

44 Ministerio de Justicia y del Derecho de Colombia, Decreto 1217 del 4 de junio de 2015, por el cual se adiciona una sección al Decreto 1069 de 2015, Único Reglamentario del Sector Justicia y del Derecho, relacionado con el trámite para corregir el componnte sexo en el Registro del Estado Civil.

45 Sentencia de la Corte Constitucional de Colombia, T-675/2017, 15 de noviembre de 2017.
} 
México si se requiriera exhibir la credencial para votar, que también solamente se expide a los adultos.

La sentencia estableció que las personas menores de edad tienen derecho a ejercer su identidad de género si concurre en el menor un grado de autonomía que sea directamente proporcional a su nivel de desarrollo y madurez. El concepto del consentimiento se estudió a la luz del cuerpo del individuo, es decir, los elementos relevantes de los rasgos fisonómicos que expresa el organismo - donde es relevante, pero no exigible, la realización de tratamientos médicos hormonales o incluso cirugías de reasignación de sexo - ; la identidad de género que la persona proyecta hacia sí y en sus relaciones sociales, y las manifestaciones o expresiones que revelen el ejercicio de su identidad de género, como el proyecto de vida o la autoconsideración del género que se desea ejercer. El requisito de mayoría de edad se pasó por un tamiz de proporcionalidad, y se concluyó que la exigencia de mayoría de edad resulta desproporcional con el derecho humano de identidad.

Sin duda, la T-675/2017 es una sentencia aditiva que añade un supuesto de procedencia para la rectificación de documentos personales en atención a la identidad de género de una persona trans. La norma jurídica no prevé la procedencia del trámite ante menores de edad, pero la jurisdicción constitucional estima apegado a derechos fundamentales que sí se autorice en menores de edad. Inclusive, un efecto peculiar de la sentencia fue ordenar a la Superintendencia Nacional de Notariado y Registro que en un plazo de treinta días emitiera una circular dirigida a todas las notarías del país para que, a la luz de la jurisprudencia constitucional, se aclare el alcance del precepto analizado y se ajusten sus actos a la sentencia.

Es particularmente relevante que en las sentencias T-477/95 y T-675/ 2017 se practicaron pruebas periciales médicas y se escuchó con atención el parecer, el proyecto de vida y la autoconcepción de la persona trans. Esto propició que el análisis constitucional no se centrara en un debate de derechos o concepciones filosóficas, sino que se centrara a datos objetivos y vivencias reales de la persona que buscaba justica.

Tal situación no se realiza en la alta jurisdicción constitucional mexicana, a excepción del señero caso de seropositividad de amparos de militares que conoció el Pleno de la Suprema Corte en 2007, donde celebró audiencias públicas con participación de expertos en materia de salud. ${ }^{46}$ La regla

\footnotetext{
46 Silva García, Fernando, "VIH y militares (criterios jurisprudenciales de la SCJN)", Cuestiones Constitucionales, México, núm. 18, 2008, pp. 309-325.
} 
de litis cerrada del juicio de amparo — que exige que los actos de autoridad se analicen tal como están probados ante la autoridad responsable- y la jurisprudencia que limita la práctica de pruebas en el recurso de revisión a casos específicos que usualmente van en contra de los intereses del justiciable - como pruebas supervinientes para acreditar la improcedencia del amparo, o rebatir la presunción de existencia del acto reclamado- ${ }^{47}$ han hecho que el trabajo de la Corte sea de índole revisionista y casacionista, en lugar de erigirse como un órgano de justicia viva.

Otro ejemplo de sentencias extranjeras de relevancia se encuentra en la reciente sentencia del Pleno del Tribunal Constitucional de España (STC 99/2019), a quien le fue cuestionada la constitucionalidad de un precepto de la Ley 3/2007, del 15 de marzo, reguladora de la rectificación registral de la mención relativa al sexo de las personas, que prevé como requisito la mayoría de edad de la persona trans. ${ }^{48} \mathrm{El}$ caso, iniciado por los padres de un menor transexual, encontró en los órganos judiciales de primera y segunda instancia una desestimación, por carecer de legitimación en la causa, toda vez que para acceder a la reasignación sexogenérica el legislador precisó el requisito de la mayoría de edad.

Llegado el caso al Tribunal Constitucional, por la vía de una cuestión de inconstitucionalidad que planteó la sala civil del Tribunal Supremo, se dictó una sentencia aditiva. La norma que exige la mayoría de edad para proceder a la rectificación de documentos del registro civil no es inconstitucional siempre que no sea aplicada a menores de edad con suficiente madurez y que se encuentren en una situación estable de transexualidad. Lamentablemente, esta sentencia fue dictada tras cinco años de iniciado el litigio, caso en la antesala que el menor transexual cumpliera la mayoría de edad. Ello revela la imperiosa necesidad de aclarar la vía de tramitar esta

\footnotetext{
47 Cfr. las tesis 2a./J. 64/98, Semanario Judicial de la Federación y su Gaceta, Novena Época, 195615, tomo VIII, septiembre de 1998, p. 400, de rubro "Pruebas en la revisión. Deben tomarse en consideración las supervenientes, Si se relacionan con la improcedencia del juicio de garantías"; y 2a./J. 60/2002, Semanario Judicial de la Federación y su Gaceta, Novena Época, tomo XVI, julio de 2002, p. 352, de rubro "Pruebas en la revisión. Deben tomarse en cuenta las documentales aportadas para desvirtuar la omisión de rendir informe justificado que se imputa en la sentencia recurrida a la autoridad responsable recurrente".

48 STC 99/2019, sentencia del Pleno del Tribunal Constitucional de España, Boletín Oficial del Estado, núm. 192, 12 de agosto de 2019.
} 
clase de asuntos, según el adagio de que la justicia tardía equivale a una denegación de justicia.

Una peculiaridad debe resaltarse: no se declara la inconstitucionalidad de la norma con efectos erga omnes, pues daría lugar a un vacío legal incluso para personas mayores de edad que pretendan adecuar sus documentos según su identidad de género. La fórmula que utilizó el tribunal constitucional español es declarar la inconstitucionalidad, pero no la nulidad, del precepto materia de la cuestión.

Esta manera de resolver fue duramente criticada en un voto particular de la vicepresidente del Tribunal, quien pone de manifiesto que se tocan ámbitos regulatorios que sólo corresponden al legislador. ${ }^{49}$ También expresa una legítima preocupación por los efectos confusos del fallo, al no precisar si se trata de una sentencia aditiva, una declaración de inconstitucionalidad parcial, una mera interpretación de la norma, o una sentencia monitoria que sugiere al legislador nuevas formas de regular un tema. El voto particular razona sobre la incertidumbre pragmática que generará la sentencia, pues no se expone qué entidad valora la suficiente madurez del menor de edad trans, bajo qué canon probatorio se acredita, o cómo se define la situación estable de transexualidad.

Las normas jurídicas de Colombia y España sobre el tema tampoco están exentas de críticas. En España, la Ley 3/2007, del 15 de marzo, reguladora de la rectificación registral de la mención relativa al sexo de las personas, en su artículo 4.1 prevé como requisito para la rectificación del sexo que haya sido "diagnosticada disforia de género y que ha sido tratada médicamente durante al menos dos años para acomodar sus características físicas a las correspondientes al sexo reclamado". Este precepto cae en una categoría sospechosa de inconstitucionalidad, y posiblemente será materia de futuras sentencias, pues parece una intromisión ilegítima al desarrollo de la personalidad que a una persona trans se le exijan documentos médicos para comprobar un ideario personal e interno como la vivencia de género. Además de que la redacción y el contenido normativo del artículo 4.1 parecen tratar la reasignación de género como una cuestión patológica que amerita comprobación y tratamiento médicos.

En cuanto a la normativa de Colombia, existe una regulación peculiar en el decreto 1217 de 2015 del Ministerio de Justicia y del Derecho, pues

49 Voto particular de la magistrada Encarnación Roca Trías en la STC 99/2019, sentencia del Pleno del Tribunal Constitucional de España, Boletín Oficial del Estado, núm. 192, 12 de agosto de 2019. 
el artículo 2.2.6.12.4.6 impone límites a la corrección de actas del registro civil, ya que no se podrá solicitar una corrección dentro de los diez años siguientes a la expedición de la reasignación, y esto sólo podrá corregirse hasta en dos ocasiones. ¿Es correcta la medida que racionaliza el número de veces que una persona puede adscribirse una identidad de género? ¿Es una invasión desproporcionada al desarrollo de la libre personalidad? Seguramente habrá batallas judiciales que respondan las cuestiones, pero basta ahora con mostrar que el legislador nacional ejerce un amplio margen de apreciación para regular los aspectos torales de la vida gregaria.

Un punto en común de las normas de España y Colombia, en el cual México debe poner especial atención, es la inmutabilidad en el número de identificación personal. No obstante que la persona trans modifique los componentes de nombre y sexo en su acta de nacimiento y demás documentos personales, no es jurídicamente posible que se cambie el número que el Estado asigna a la persona para controlar sus derechos y obligaciones. El artículo 2.2.6.12.4.3 del decreto colombiano dispone que la corrección no modifica el número único de identificación personal (NUIP), mientras que el artículo 6.2 de la española Ley 3/2007, del 15 de marzo, dispone que en todo caso se conservará el mismo número del documento nacional de identidad.

Como se apuntó líneas arriba, la CURP es el único dato alfanumérico que dispone el gobierno federal de México para controlar la identidad de las personas, pero en sus componentes se incluyen letras que revelan el nombre y el sexo de la persona, los cuales serían modificados en casos de reasignación de género. Ésta es una asignatura pendiente que debe ser zanjada por el legislador.

Finalmente, existen ejemplos en que el soft law ha propiciado normas jurídicas estatales para la protección jurídica de la comunidad transexual. Los contenidos del soft law, si bien ausentes de la cualidad de heteronomía que caracteriza a las normas jurídicas duras (hard law) que se imponen obligatoriamente al operador jurídico, han permeado para mejorar los estándares de protección de los derechos de las personas. Por ejemplo, la resolución 2048 de la Asamblea parlamentaria del Consejo de Europa fue tomada en consideración por Francia para modificar su legislación y prácticas jurisprudenciales. ${ }^{50}$ Esta resolución, en cuanto al derecho de identidad de personas trans, en su punto 6.2.1 hizo un llamado a los Estados

\footnotetext{
50 Gerry-Vernières, Stéphane, "Droit à la vie privée et familiale...", cit.
} 
europeos para prever procedimientos rápidos, transparentes y accesibles, basados en la autodeterminación personal, para que las personas cambien su nombre y sexo en documentos personales. ${ }^{51}$

Como se ve, diversos países tienen discusiones más avanzadas en la materia, y en México los pasos son exiguos y se han dado básicamente por la actividad casuística de los tribunales federales a través del juicio de amparo. Las discusiones en México han versado sobre si el procedimiento administrativo o judicial es el más adecuado, cuando en el resto de países la modificación trans se realiza ante autoridades administrativas, como el registrador civil o un notario público. Hemos discutido en México si se impone una anotación marginal o no; o inclusive qué especialización debe tener el tribunal de amparo que resuelve las controversias del registro civil en casos de personas trans.

El retraso normativo que padece México, antes de desalentar o tomarse como un tercermundismo jurídico, debiera motivar al Poder Legislativo para actualizar los códigos y ser más sagaces en la creación de normas jurídicas con contenidos que atiendan los desafíos que exige la vorágine tecnológica en que vivimos inmersos. México es una potencia económica, una de las veinte economías más grandes del mundo, que, por ejemplo, carece de regulación sobre calentamiento global, comercio electrónico, o gobierno digital, o acciones afirmativas específicas para favorecer a comunidades desventajas.

\section{HACIA UNA SENTENCIA ESTRUCTURAL DE LA SuPREMA CORTE DE JUSTICIA DE LA NACIÓN}

El comportamiento de los tribunales constitucionales ha sido objeto de fecundos estudios por la literatura constitucional. Hay un incesante debate sobre el activismo judicial y la self restraint que debe prevalecer en la práctica judicial..$^{52}$ Jueces constitucionales han expresado que debe existir un control constitucional vigoroso, pero prudente y responsable, y que los tribunales constitucionales viven un dilema trágico: o la osadía extrema,

51 Asamblea Parlamentaria del Consejo de Europa, Resolution 2048, Discrimination against transgender people in Europe, 22 de abril de 2015.

52 Torres, Luis Fernando, "El activismo judicial en la era neoconstitucional", Iuris Dicto. Revista del Colegio de Jurisprudencia de la Universidad San Francisco de Quito, año 13, vol. 15, 2013, pp. 65-80. 
incluso irresponsable, o la moderación excesiva, que equivale a veces a un retiro cobarde. ${ }^{53}$

¿Hasta qué grado un tribunal constitucional debe anular normas jurídicas creadas por el legislador? En la medida en que pueda salvarse la presunción de constitucionalidad de la norma, ésta debe preservarse, pues el tribunal no busca la inconstitucionalidad de la norma, sino que la presume apegada a la Constitución. La deferencia al legislador sugiere considerar al Poder Legislativo como el órgano donde se solventan las discrepancias políticas mediante la representación democrática. El lugar para debatir sobre los temas que provocan un mayor dilema moral es el parlamento, y no el tribunal constitucional. ${ }^{54}$

¿Interpretar un precepto permite a la jurisdicción constitucional, en vez de anular la norma, fijar interpretaciones adicionales no previstas en el texto? La respuesta es afirmativa, y por eso los tribunales constitucionales han desarrollado una pluralidad de efectos en sus sentencias para que se respete el ordenamiento constitucional y no se generen vacíos legales.

En un grado más avanzado de osadía judicial, ¿pueden los tribunales constitucionales dar lineamientos e imponer plazos al legislador para que cree normas jurídicas? En este aspecto, las sentencias estructurales se ponen en relieve, y deberían ser utilizadas como catalizador de los derechos fundamentales de las personas, sobre todo de grupos sociales que padecen discriminación, marginación o exclusión.

Ante un ordenamiento legal configurado por el Poder Legislativo, el tribunal constitucional extrae significados y los dota de eficacia. Se reitera, en el tema de la identidad de personas transgénero salta a la vista que con las normas jurídicas constitucionales que reconocen el principio de progresividad (artículo 1o., tercer párrafo), el derecho a la igualdad (artículo 4o., octavo párrafo), la prohibición de todo acto de discriminación (artículo 1o., último párrafo), el derecho a la identidad (artículo 4o., primer párrafo), los principios de competencia administrativa y reserva de ley que rigen al registro civil (artículo 130, penúltimo párrafo) y el mandato al Congreso de la Unión para armonizar y homologar los registros civiles (ar-

\footnotetext{
53 Martínez Caballero, Alejandro, "Tipos de sentencias en el control constitucional de las leyes: la experiencia colombiana”, Revista de Estudios Socio-Jurídicos, Bogotá, vol. 2, núm. 1, 2000, pp. 8-32.

54 De Lora, Pablo, “Justicia constitucional y deferencia al legislador", en Laporta, Francisco (ed.), Constitución: problemas filosóficos, Madrid, Centro de Estudios Políticos y Constitucionales, 2003, pp. 345-370.
} 
tículo 73, fracción XXIX-R), se tiene un andamiaje suficiente para que la Suprema Corte sea creativa, osada y emita una auténtica acción afirmativa para resolver una violación constante de derechos fundamentales.

Una sentencia puede ser leída como la culminación de un proceso que es puesto al conocimiento de un tribunal, pero en materia constitucional la sentencia es sobre todo la voz emitida por un órgano del Estado de enorme envergadura. ${ }^{55}$ Hay diversos ejemplos en que causas judiciales llevadas por ciudadanos han propiciado cambios profundos en la producción normativa o en la corrección de prácticas administrativas o judiciales, particularmente en la consecución de derechos sociales. ${ }^{56}$ Inclusive, una jurisprudencia laxa con el respeto de los derechos humanos daña sistemáticamente las prerrogativas ciudadanas, y el desaseo judicial se traduce en actos atroces para la persona. Esto sucedió en México, por ejemplo, con las tesis emitidas en el sistema penal inquisitorio, en que los derechos del imputado se desplazaron por privilegiar los actos de investigación del Ministerio Público o la formalidad tramposa de los tribunales penales. ${ }^{57}$

La jurisdicción constitucional, más que enmarcarse en el añejo sistema de pesos y contrapesos, debe trascender a un diálogo democrático con el resto de poderes del Estado. Según Gargarella, el control de poder en términos de pesos y contrapesos se gestó con la intención de evitar la guerra que surgiría si un poder asume el control del resto de decisiones de la vida pública, imponiendo su voluntad al resto de ramas del gobierno. ${ }^{58}$ Entonces, la justicia constitucional debe pisar otros terrenos para motivar una auténtica interacción entre todos los órganos de poder político.

Es posible fijar una tipología de las sentencias del tribunal constitucional cuando efectúa el control abstracto de validez constitucional de normas generales. Para este efecto se sigue a Rosario Serra. ${ }^{59}$

55 García Roca, Javier, El conflicto entre órganos constitucionales, Madrid, Tecnos D. L., 1987, pp. 175-178.

56 Gargarella, Roberto, "Justicia dialógica en la ejecución de los derechos sociales: Algunos argumentos de partida", en Yamin, Alicia Ely et al. (coord.), La lucha por los derechos de la salud: ¿puede la justicia ser una herramienta de cambio?, Buenos Aires, Siglo XXI, 2013, pp. 279 a 294.

57 Magaloni, Ana Laura, "El ciudadano olvidado", en Vázquez, Rodolfo (coord.), Corte, jueces y politica, México, Fontamara, 2007, pp. 111-120.

58 Gargarella, Roberto, "El papel del poder judicial dentro del nuevo 'constitucionalismo dialógico'”, en González, Felipe et al. (coord.), ¿Quién manda aquí?: la crisis global de la democracia representativa, Barcelona, Debate, 2017, pp. 85-102.

59 Serra Cristóbal, Rosario, La guerra de las cortes, Madrid, Technos, 1999, p. 60. 
Existen sentencias correctoras o adequatrici, en que la norma no es inconstitucional si se le atribuye un significado compatible con los valores constitucionales. Aquí encontramos, por ejemplo, la interpretación conforme, a fin de evitar la declaración de inconstitucionalidad de una norma y poner en su lugar una reinterpretación corregida.

Hay sentencias manipulativas cuando se extraen dos interpretaciones de una disposición y se expulsa una de ellas, la que no es compatible con la Constitución. Por ejemplo, históricamente la Suprema Corte interpretó el artículo 133 constitucional para poner de manifiesto que el control difuso no es permitido por la Constitución, aun cuando expresamente la Constitución sí lo autoriza. ${ }^{60}$ Este malabar jurídico fue abandonado por el Pleno el 2011, al resolver el expediente Varios 912/2010.

Las sentencias acumulativas o aditivas declaran inconstitucional una norma, pero deducen del texto una nueva interpretación, que trae como consecuencia la creación de una norma positiva. Esto ocurrió en el amparo en revisión 1317/2017 de la Primera Sala, en que se declaró inconstitucional el sistema normativo de rectificación de actas del registro civil del estado de Veracruz, por no proveer un trato igualitario a casos de reasignación sexogenérica. Se declaró que las normas civiles son inconstitucionales, y a la vez se dedujo que la vía administrativa es la adecuada.

Son sustitutivas las sentencias que señalan otra norma que debe ponerse en lugar de la contenida en el texto de la norma declarada inconstitucional. Como ejemplos pueden citarse las jurisprudencias 1a./J. 46/2015 (10a.) ${ }^{61}$ y 1a./J. 10/2019 (10a.), ${ }^{62}$ ambas de la Primera Sala, que respectivamente declararon inconstitucionales las legislaciones estatales que no autorizan

60 Tesis P./J. 74/99, Semanario Judicial de la Federación y su Gaceta, Novena Época, 193435, tomo X, agosto de 1999, p. 5, de rubro "Control difuso de la constitucionalidad de normas generales. No lo autoriza el artículo 133 de la Constitución”. Cfr. Gudiño Pelayo, José de Jesús, "Lo confuso del control difuso de la Constitución. Propuesta de interpretación del artículo 133 constitucional", Revista de la Facultad de Derecho de México, México, núm. 244, 2005, pp. 79-110.

61 Tesis 1a./J. 46/2015 (10a.), Gaceta del Semanario Judicial de la Federación, Décima Época, 2009922, libro 22, septiembre de 2015, tomo I, p. 253, de rubro: "Matrimonio entre personas del mismo sexo. No existe razón de índole constitucional para no reconocerlo".

62 Tesis 1a./J. 10/2019 (10a.), Gaceta del Semanario Judicial de la Federación, Décima Época, 2019365, libro 63, febrero de 2019, tomo I, p. 493, de rubro: "Inconstitucionalidad de la prohibición absoluta al consumo lúdico o recreativo de marihuana prevista por La Ley General de Salud". 
el matrimonio entre personas del mismo sexo y la prohibición absoluta del consumo lúdico de marihuana. Los alcances de estos fallos consistieron en imponer al derecho positivo hipótesis de procedencia que el legislador no reguló.

Las sentencias-delegación declaran la ilegitimidad constitucional de una norma e indican una serie de principios que la nueva ley reguladora de la materia habría debido tener en cuenta para resultar compatible con la Constitución. La vocación de este tipo de sentencias se plasmó en el amparo directo 9/2018 de la Segunda Sala, que ambiciosamente ordenó la creación paulatina de un programa especial de seguridad social para trabajadoras domésticas — con coberturas de riesgos de trabajo, enfermedades, maternidad, guardería, invalidez y retiro--, pues han sido un grupo social vulnerable e invisible para el estado de bienestar. ${ }^{63}$

La tipología de sentencias del tribunal constitucional ayuda a evidenciar que el control abstracto de leyes no es una cuestión sencilla ni intelectualmente cómoda. Los efectos de una posible anulación de una norma serían perniciosos si se deja un vacío legal entretanto el legislador corrige la norma defectuosa, y por eso hay que ser cautos con la solución dada a los casos. ${ }^{64}$

Las sentencias correctoras tienen su origen en el contencioso-administrativo para señalar qué órgano del Estado asume la titularidad de una competencia o función pública. ${ }^{65}$ Trasladada esta idea a la jurisdicción constitucional, se propicia el diálogo entre un poder del Estado con los otros. Muchas sentencias constitucionales no debieran sólo agotar la instancia de un particular proceso con efectos inter partes, sino propulsar una coordinación con diversas instituciones del Estado.

A efectos de esta investigación, consideremos que pura y duramente se declare inconstitucional la vía jurisdiccional para la rectificación de actas

63 Segunda Sala de la Suprema Corte de Justicia de la Nación, sentencia dictada en el amparo directo 9/2018, en sesión del 5 de diciembre de 2018. De esta sentencia surgió la tesis 2a. XXX/2019 (10a.), Gaceta del Semanario Judicial de la Federación, Décima Época, libro 66, mayo de 2019, tomo II, p. 1544, de rubro: “Trabajo del hogar. El artículo 13, fracción ii, de la Ley del Seguro Social es inconstitucional al excluir a los trabajadores domésticos de ser sujetos de aseguramiento al régimen obligatorio, debido a que viola el derecho humano a la seguridad social en igualdad de condiciones".

64 Martínez Caballero, Alejandro, "Tipos de sentencias en el control constitucional de las leyes...", cit.

65 García Roca, Javier, El conflicto entre órganos constitucionales, cit. 
del registro civil, por estimarla contraria a la igualdad en casos de personas trans. Futuros casos se verían mermados, por la falta de normas reguladoras, para quien tuviera la necesidad de modificar el acta para cuestiones relacionadas con correcciones ortográficas de nombres, o fijación de parentescos tras juicios de paternidad. Una norma es inconstitucional aplicada en un cierto contexto, pero sus efectos ilegítimos desaparecen en otro ámbito de aplicación.

De igual forma, si se declarara inconstitucional la anotación marginal que se plasma en el acta de nacimiento de personas trans - anotación en la que constan los datos de corrección que tuvieron lugar por la reasignación sexogénerica - se quitaría al Estado su función controladora de los actos del registro civil, pues sería prácticamente imposible dar seguimiento a las personas que han reasignado su sexo. Sin rastro ni registro alguno, ciertamente se tendrían escenarios regresivos por la falta de identificación de personas y su posible evasión de obligaciones adquiridas — de la índole penal, tributaria, civil o patrimonial - o pérdida de derechos que correspondan -laborales, sucesorios o prestacionales-.

La Suprema Corte mexicana paulatinamente ha explorado la diversidad de sentencias que puede emitir como tribunal constitucional. Poco a poco, aunque todavía sin lograrlo de lleno, se ha abandonado una visión casacionista, pues en los últimos años es más común escuchar en las deliberaciones de los ministros en el Pleno o leer en las sentencias, la autoalusión de ser el tribunal constitucional de México y la importancia que tendrán los efectos de las sentencias.

La innovación en los efectos de las sentencias también ha cambiado, a fin de paulatinamente repensar la fórmula de Otero. El primer caso de omisión legislativa en México versó sobre la ausencia de legislación reglamentaria del artículo 134 constitucional en materia de gastos de comunicación social gubernamental, a lo cual estaba conminado el Congreso de la Unión por mandato expreso de la Constitución. Una asociación civil promovió un juicio de amparo, que al llegar a la Primera Sala permitió reflexionar sobre el deber del Poder Legislativo en cumplir con los deberes de producción normativa que la Constitución le impone. ${ }^{66}$ Así, se concedió

66 Primera Sala de la Suprema Corte de Justicia de la Nación, sentencia dictada en el amparo en revisión 1359/2015, resuelto en sesión del 15 de noviembre de 2017. De esta sentencia surgió la tesis 1a. LVIII/2018 (10a.), Gaceta del Semanario Judicial de la Federación, Décima Época, 2017065, libro 55, junio de 2018, tomo II, p. 965, de rubro: "Juicio de amparo indirecto. Es procedente contra omisiones legislativas". 
el amparo para señalar una fecha límite a la legislatura federal para que emita la legislación que constitucionalmente estaba obligada, tal como lo preveía el artículo tercero transitorio de la reforma del 10 de febrero de 2014.

Otro efecto innovador se dio en la Segunda Sala, en la antes reseñada sentencia estructural, que obligó al Instituto Mexicano del Seguro Social a generar un programa piloto para la seguridad social de trabajadoras domésticas. Un juicio laboral que como muchos más pudo resolverse inter partes para reconocer a una trabajadora, prestaciones e indemnizaciones económicas, dio un viraje para visibilizar a un grupo social estructuralmente discriminado.

En materia de reasignación de sexo o de respeto a la identidad de género en miembros de la comunidad trans, ciertamente no existe un mandato constitucional expreso que obligue a legislar sobre la materia, ni están dados los linderos conceptuales ni la temporalidad a la que está sujeta una legislatura. Propiamente hablando no estamos ante una omisión legislativa.

Sin embargo, sí existe un deber constitucional plasmado en la reforma del 5 de febrero de 2017, para que el Congreso de la Unión ejerza la facultad del artículo 73, fracción XXIX-R, sobre legislación general de homologación de registros civiles, reforma cuyo artículo tercero transitorio ordena que particularmente se atienda a grupos en situación de especial vulnerabilidad y marginación. En este marco, sin duda, debiera tener cabida una legislación nacional que permita la reasignación de género para quien libremente ha decidido hacerlo.

Como se apuntó líneas arriba, con los elementos constitucionales que actualmente se tienen es posible que la Suprema Corte emita una sentencia estructural para que gubernamentalmente se atienda el derecho a la identidad de este grupo social, desde la legislación y desde las prácticas administrativas.

La idea de sentencia estructural deviene de los structural injuctions de la jurisprudencia estadounidense, en que algunos jueces adoptaron medidas para remediar situaciones graves y generalizadas que resultan contrarias a la Constitución. ${ }^{67}$ El caso prototipo es Brown vs. Board of Education,

67 Osuna, Néstor, "Las sentencias estructurales. Tres ejemplos de Colombia", en Bazán, Víctor (ed.), Justicia constitucional y derechos fundamentales, Bogotá, núm. 5, 2015, pp. 90-116. 
que en 1954 incidió en abatir la segregación racial estadounidense en materia de educación pública. ${ }^{68}$

Siguiendo a Néstor Osuna, las sentencias estructurales en la jurisdicción constitucional de Colombia han contribuido en mejorar el statu quo en materia de hacinamiento carcelario, desplazamiento de víctimas de conflictos armados internos, o la precariedad en los servicios de salud.

El contexto en que se dictan aparece: i) la vulneración masiva y generalizada de derechos fundamentales; ii) una prolongada omisión de las autoridades competentes en la materia; iii) prácticas que son contrarias a la Constitución; iv) la ausencia de medidas legislativas, reglamentarias o presupuestales para atender la problemática; v) un problema social que implica la participación de diversas entidades, y vi) el litigio individual de cada persona agraviada generaría un congestionamiento judicial y la ralentización en la protección del derecho vulnerado.

Estos aspectos aparecen en la situación de personas transexuales que pretenden reajustar sus documentos personales para que su identidad corresponda con el género que libremente sienten y viven. Si bien no existen datos oficiales sobre el número de personas transexuales, la litigiosidad de sus derechos y la falta de unicidad en las soluciones dejan entrever que su derecho a la identidad personal no es respetado. Hacen falta normas jurídicas que regulen la manera en que su reasignación de género en documentos personales se ejerce, así como una regulación específica que homologue actuaciones y prácticas en los registros civiles de las entidades federativas que no solucionan el problema. La falta de atención y cobertura del derecho a la identidad implica una patente vulneración a su derecho fundamental, que se hace más fuerte al recaer sobre individuos pertenecientes a un grupo social culturalmente discriminado.

La solución implica la participación de una pluralidad de autoridades, el Congreso de la Unión para emitir legislación general sobre la materia, si bien cada congreso estatal puede adecuar su legislación. La Secretaría de Gobernación, para adecuar la CURP de las personas o, de una vez por todas, dar pasos serios y continuados para el cumplimiento del mandato legal de tener una cédula de identidad ciudadana con registros de todos los mexicanos.

Sendas autoridades administrativas deben adecuar sus procedimientos para que la persona que ha reasignado su sexo, sin dilaciones ni necesidad

68 Brown et al. vs. Board of Education of Topeka, sentencia de la Corte Suprema de los Estados Unidos, 17 de mayo de 1954, caso 347 U.S. 483. 
de aportar mayores pruebas, corrija sus documentos personales. Por vía de ejemplo, el Instituto Mexicano de Seguridad Social para la protección a la salud o las prestaciones económicas de seguridad social; las secretarías de educación, tanto federal como estatales, para la corrección de documentos escolares o cédulas profesionales; universidades públicas o privadas, para la emisión de un título universitario; el Servicio de Administración Tributaria, para la continuidad de las obligaciones fiscales; las procuradurías federal y estatal donde nació o resida la persona, para control de posibles responsabilidades penales; fiscalías y supremos tribunales de justicia de las entidades federativas, para la continuidad de derechos y obligaciones contraídas o futuras. Sin duda, esta información ha de manejarse con absoluta reserva y confidencialidad, accediendo a la misma por requerimiento judicial o ministerial.

Asimismo, el litigio individual de cada persona ralentiza enormemente la cristalización del derecho a la identidad de la persona trans, además de lesionar la gratuidad. La fórmula de Otero es un pilar característico del juicio de amparo mexicano, la que dota a la sentencia de amparo con efectos inter partes, es decir, solamente para proteger a quienes personalmente han litigado esa causa.

Sin embargo, la actividad contemporánea de los tribunales constitucionales sugiere tener más osadía para motivar un diálogo público en causas específicas que atañen la lucha por los derechos fundamentales. Ya hubo visos de este tipo de resoluciones en materia de seguridad social de empleadas domésticas, y esta actitud debiera reiterarse. Existen elementos fácticos y jurídicos de peso que revelan la necesidad de dictar una sentencia estructural para salvaguardar genuinamente el derecho a la identidad de la comunidad trasnsexual.

Un aspecto distintivo de las sentencias estructurales es el mecanismo de cumplimiento. No se trata del procedimiento común de ejecución de las sentencias de amparo - por ejemplo, de restituir derechos individuales, anular el acto viciado o retrotraer las actuaciones de un juicio-, sino más bien de propiciar un diálogo abierto y fecundo con otros órganos del Estado. En las sentencias estructurales, las órdenes de cumplimiento son abiertas, a fin de motivar un cambio en el sistema jurídico nacional, respetando el margen de apreciación de cada órgano y el despliegue de sus competencias. ${ }^{69}$

69 Osuna, Néstor, "Las sentencias estructurales...", cit. 
Asimismo, son particularmente relevantes los mecanismos de cumplimiento que implementa el tribunal constitucional para verificar que la sentencia estructural ha sido cumplida, imponiendo requisitos laxos para ser deferente con el legislador o las agencias del Ejecutivo, o siendo rigurosos con la creación de Salas ad hoc dentro del tribunal que den seguimiento a cumplimientos complejos. ${ }^{70}$

La doctrina Chevron de la Suprema Corte estadounidense incorporó el principio de deferencia a la administración pública para que interpreten y apliquen el derecho administrativo en las agencias gubernamentales. ${ }^{71} \mathrm{Si}$ bien el órgano Judicial ostenta la última palabra en la interpretación de la ley, son las agencias gubernamentales las que proyectan el contenido legal en actos específicos, y de manera cotidiana dotando de significado y practicidad a las normas abstractas.

Esta deferencia también debe tomarse en cuenta por la Suprema Corte mexicana, pues no parece adecuado que se den órdenes estrictas para homologar o rectificar las prácticas de treinta y dos direcciones del registro civil que existen en México. Tampoco es conveniente que el tribunal constitucional entre en discusiones que despiertan posiciones morales intrincadas, que sin duda se levantan al hablar de grupos de la diversidad sexual y la lucha por los derechos que indudablemente tienen por el solo hecho de ser personas. ${ }^{72}$ La palestra pública es el parlamento, y ahí deben librarse las batallas conceptuales y políticas, no en el tribunal constitucional.

La Suprema Corte debería asumir un activismo judicial moderado para zanjar la incertidumbre jurídica que prima en los actos del registro civil de personas que han decidido libremente reasignar el sexo. Pero, en atención a la separación de poderes y la deferencia al legislador, por ningún motivo debe llegar al grado de definir el contenido específico de las normas.

Como se muestra en los datos de derecho comparado plasmados en este ensayo, el debate de derechos de la comunidad trans se encuentra en el

70 Cruz Rodríguez, Michel, "Decisiones estructurales y seguimiento judicial en Colombia (1997-2017)", Revista Española de Derecho Constitucional, Madrid, núm. 117, 2019, pp. 167-202.

71 Vázquez Alonso, Víctor, "Deferencia judicial hacia las agencias federales y deferencia hacia el legislador: la interpretación de la ley defectuosa y el principio democrático en la sentencia King v. Burwell”, Revista General de Derecho Constitucional, España, núm. 26, 2018.

72 De Lora, Pablo, Justicia constitucional y deferencia al legislador, cit. 
derecho a la adopción, ${ }^{73}$ en la posibilidad de que menores de edad ejerzan la reasignación de sexo, en la validez de exigir el acreditamiento de procedimientos médicos para reasignar el sexo, o en el consentimiento que los padres deben dar en casos en que un menor de edad decida ejercer su libre vivencia de género. ${ }^{74}$

No es conveniente que la Suprema Corte abruptamente pase de la concesión de amparos individuales para restituir los derechos de personas trans, a la exigencia de inmediatamente aprobar legislación con ciertos contenidos. El activismo también debe respetar la división de poderes, permitiendo que las agendas legislativas se desarrollen en los procedimientos formales de creación del derecho. Podría exhortarse a los entes legitimados por el artículo 71 constitucional para la iniciativa legislativa, que se propongan los contenidos específicos.

En suma: el derecho a la identidad es uno de los aspectos más elementales del ser humano, pues incide en aspectos tan básicos como la identificación plena ante el Estado y particulares, la correspondencia de documentos personales con la identidad propia de la persona, y su legítima intención de vivir plenamente en el género que se ha elegido. La cada día más frecuente judicialización de casos individuales hace necesario que se atienda estructuralmente la cuestión, para dar un paso realmente importante en la materia.

Una propuesta de sentencia estructural sobre el derecho de identidad de personas transgénero podría tener los siguientes efectos:

1. Exhortar al Congreso de la Unión para que en un plazo razonable emita una ley general que armonice y homologue la organización y funcionamiento de los registros civiles, con particular énfasis en un grupo vulnerable como la comunidad transgénero. Esto, conforme el artículo tercero transitorio de la reforma constitucional publicada el 5 de febrero de 2017, respecto al artículo 73, fracción XXIX-R de la Constitución federal.

2. Exhortar a los entes legitimados para la iniciativa de ley enunciados en el artículo 71 de la Constitución federal —presidente de la República, diputados y senadores del Congreso de la Unión, legislaturas

73 Von Stritzky, Johannes, "El desarrollo de la protección jurídica de las personas homosexuales, bisexuales, transexuales e intersexuales (LGBT) en Alemania", cit.

74 De Montalvo Jääskeläinen, Federico, "Problemas legales acerca del tratamiento médico de la disforia de género en menores transexuales", cit. 
estatales y a la iniciativa ciudadana - a través de una publicación en el Diario Oficial de la Federación para que, en el marco de sus competencias y agendas políticas, presenten iniciativas que doten de contenido a la ley general de registro civil, en cuanto a los procedimientos de reasignación sexo genérica.

3. Exhortar a las legislaturas de las entidades federativas para que, en el marco de sus competencias, tomen en consideración las consideraciones vertidas en la sentencia estructural de la Suprema Corte, y que modifiquen la normativa que limite o restrinja el derecho de identidad de personas trasngénero en los procedimientos de reasignación sexogenérica.

4. Exhortar a las legislaturas de las entidades federativas para que ajusten la normativa local a los contenidos de la futura ley general de registro civil que emita el Congreso de la Unión conforme el artículo 73, fracción XXIX-R, de la Constitución federal.

5. Exhortar a la Secretaría de Gobernación para que, en el marco de sus competencias y presupuestos, promueva un programa nacional e integral para la implementación de la cédula de identidad ciudadana prevista en la Ley General de Población (artículos 97 y 111) y la Ley de Migración (artículo 36, fracción II ); sugiriendo que se tome en consideración el Acuerdo sobre el programa de establecimiento del registro nacional de ciudadanos y la expedición de la cédula de identidad ciudadana, publicado en el Diario Oficial de la Federación el 30 de junio de 1997.

6. Exhortar a la Secretaría de Gobernación para que considere qué medidas administrativas implementar para la corrección de datos de la CURP en personas que han ejercido su reasignación de género, teniendo en cuenta que en la clave alfanumérica de la persona transgénero debe corresponder la letra del sexo con su nueva identidad de género.

7. Exhortar la creación de un comité integrado por las secretarías federales de Gobernación, de Relaciones Exteriores, y de Seguridad Pública y Seguridad Ciudadana; la Fiscalía General de la República, y el Consejo de la Judicatura Federal, para que en el marco de sus competencias y presupuestos generen una base de datos que resguarde los procedimientos administrativos y resoluciones jurisdiccionales sobre personas que han reasignado su condición sexogenérica. 
Asimismo, que en la creación, implementación y acceso de la base de datos tengan participación activa y eficaz las fiscalías, las direcciones del registro civil y los supremos tribunales de justicia de las treinta y dos entidades federativas.

8. Exhortar a las direcciones del registro civil de las entidades federativas para que, en el marco de sus competencias, tomen en cuenta las consideraciones vertidas en la sentencia estructural de la Suprema Corte, y, en consecuencia, reajusten las prácticas que limiten o restrinjan el derecho de identidad de personas transgénero en los procedimientos de reasignación sexogenérica.

Una sentencia estructural no es cómoda para el poder político ni para la Suprema Corte, pues los pone en un plano protagónico en temas que encienden debates morales en la conservadora sociedad mexicana. Sin embargo, una sentencia estructural cubre tres propósitos: permite a la Suprema Corte afianzar su rol de tribunal constitucional, la hace dialogar frontalmente con todos los poderes del Estado y aproxima los derechos humanos a la vida cotidiana de las personas. Tres propósitos que, indudablemente, ameritan la sagaz intervención de nuestro tribunal constitucional.

\section{EPÍLOGO}

Después de la investigación y redacción de este ensayo, la Segunda Sala de la Suprema Corte resolvió una contradicción de tesis sobre criterios de tribunales colegiados que han sido analizados en este ensayo. ${ }^{75} \mathrm{La}$ sentencia aún no se publica, pero la versión taquigráfica de la sesión revela que se estableció que, según las legislaciones de Chihuahua y Guanajuato, la rectificación de actas del registro civil en casos de reasignación sexogenérica debe tramitarse en la vía administrativa y no en la judicial. Incluso la tesis de jurisprudencia aprobada en la sesión está redactada en ese sentido.

Este criterio no zanja la cuestión planteada en este ensayo. Solamente fija un criterio jurídico respecto a dos entidades federativas, aclarando en qué vía debe tramitarse la corrección de las actas del registro civil. Inclusive, como se ha planteado en este ensayo, la jurisprudencia de la Suprema Corte carece de obligatoriedad para órganos distintos que los judiciales,

75 Segunda Sala de la Suprema Corte de Justicia de la Nación, sentencia dictada en la contradicción de tesis 346/2019, en sesión del 21 de noviembre de 2019. 
por lo que podría esperarse que los oficiales del registro civil y las legislaturas de los estados actúen en una vía distinta. Ello obligaría, otra vez, a la promoción individual de amparos indirectos para que la jurisprudencia se aplique por los jueces de distrito y, ahora sí, se respete la vía administrativa para la adecuación de las actas del registro civil.

La propuesta de una sentencia estructural continúa vigente para intentar resolver a fondo el problema. El hecho de que la Corte a posteriori a esta investigación haya resuelto otro caso de manera casuística, sin atajar el problema global, sólo revela que es insuficiente la emisión de sentencias con aplicación minimalista, en este caso ceñidas a la legislación de dos entidades federativas.

La reciente sentencia de la Segunda Sala tampoco agota el tema. Tratándose de derechos fundamentales y su garantía en los tribunales, las respuestas y propuestas deben seguir fluyendo para enriquecer el debate público sobre temas tan complejos e interesantes.

\section{BIBLIOGRAFÍA}

CAntoral Domínguez, Karla. "El derecho a la identidad del menor: el caso de México", Revista Boliviana de Derecho, La Paz, núm. 20, 2015.

CONSEJO PARA PREVENIR Y ELIMINAR LA DISCRIMINACIÓN DE LA CIUDAD DE MÉXICO, Población LGBTTTI, actualización mayo 2018, disponible en: https://copred.cdmx.gob.mx/storage/app/uploads/public/5b1/ff9/ f94/5b1ff9f945326665643161.pdf, el 14-08-2019, 12:06 hrs.

CRUz RodríGUEZ, Michel, "Decisiones estructurales y seguimiento judicial en Colombia (1997-2017)", Revista Española de Derecho Constitucional, Madrid, núm. 117, 2019.

DE LORA, Pablo, "Justicia constitucional y deferencia al legislador", en LAPORTA, Francisco (ed.), Constitución: problemas filosóficos, Madrid, Centro de Estudios Políticos y Constitucionales, 2003.

De Montalvo JÄÄSKelÄInen, Federico, "Problemas legales acerca del tratamiento médico de la disforia de género en menores transexuales", Revista General de Derecho Constitucional, Madrid, núm. 24, 2017.

DINA, Eduardo y ESPEJEL, Citlalli, "Si ahora soy Ofelio, soy el más bonito que existe", El Universal, 11 de agosto de 2019. 
ELÓSEGUi ITXASO, María, "El TJCE y el matrimonio de transexuales. Una interpretación «Ultra vires»”, Unión Europea Aranzadi, España, núm. 5, 2004.

FIX-FIERro, Héctor et al., Constitución política de los Estados Unidos Mexicanos. Texto reordenado y consolidado, México, UNAM, 2016.

GARCÍA ROCA, Javier, El conflicto entre órganos constitucionales, Madrid, Tecnos, 1987.

GARGARELlA, Roberto, "Justicia dialógica en la ejecución de los derechos sociales: Algunos argumentos de partida", en YAMIN, Alicia Ely et al. (coord.), La lucha por los derechos de la salud: ¿puede la justicia ser una herramienta de cambio?, Buenos Aires, Siglo XXI, 2013.

GARGARElla, Roberto, "El papel del Poder Judicial dentro del nuevo «constitucionalismo dialógico»", en GONZÁLEZ, Felipe et al. (coord.), ¿Quién manda aquí?: la crisis global de la democracia representativa, Barcelona, Debate, 2017.

GERRY-VERNIÈRES, Stéphane, "Droit à la vie privée et familiale. Le soft law dans le domaine des droits fondamentaux", Revue trimestrielle des droits de l'homme, Paris, núm. 110, 2017.

GudiÑo Pelayo, José de Jesús, "Lo confuso del control difuso de la Constitución. Propuesta de interpretación del artículo 133 constitucional", Revista de la Facultad de Derecho de México, México, núm. 244, 2005.

GuILABERT, Aurelien, "Identidad y salud TTTranserval", El Sol de México, 12 de agosto de 2019.

MAgAloni, Ana Laura, "El ciudadano olvidado", en VÁZQUEZ, Rodolfo (coord.), Corte, jueces y politica, México, Fontamara, 2007.

MARTínez CABAllero, Alejandro, "Tipos de sentencias en el control constitucional de las leyes: la experiencia colombiana", Revista de Estudios Socio-Jurídicos, Bogotá, vol. 2, núm. 1, 2000.

MiLl, John Stuart, Sobre la libertad, trad. de Pablo de Azcárate et al., México, Gernika, 1991.

Monereo Atienza, Cristina, Diversidad de género, minorías sexuales y teorias feministas: superposiciones entre las teorias de lesbianas, gays, bisexuales y transexuales y el feminismo en la reformulación de conceptos y estrategias politico-jurídicas, Madrid, Dykinson-Universidad Carlos III, Instituto de Derechos Humanos, 2015. 
NAVARro BATISTA, Nicolás, "Los transexuales en la jurisprudencia europea: comentario al asunto K.B. (sentencia del TJCE de 7 de enero de 2004, as. C-117/01)", Revista General de Derecho Europeo, núm. 4, 2004.

Orozco Pulido, Jesús Manuel, "La Suprema Corte de Justica de México y su sistema de creación jurisprudencial: defectos y retos", en Cucarella, Luis (coord.), Derecho procesal convencional. El nuevo desafio de la justicia constitucional, Bogotá, Ediciones Nueva Jurídica, 2016.

OsunA, Néstor, "Las sentencias estructurales. Tres ejemplos de Colombia”, en BAZÁN, Víctor (ed.), Justicia constitucional y derechos fundamentales, Bogotá, núm. 5, 2015.

Pizzorusso, Alessandro, "Recientes tendencias del parlamentarismo", Revista Vasca de Administración Pública, Bilbao, núm. 39, 1994.

SAmuel, Alec, "Consolidation: A plea", Statute Law Review, Oxford, vol. 59, Oxford University Press, 2005.

SERra CRIstóbal, Rosario, La guerra de las cortes, Madrid, Tecnos, 1999.

SILVA GARCÍA, Fernando, "VIH y militares (criterios jurisprudenciales de la SCJN)", Cuestiones Constitucionales, México, núm. 18, 2008.

Soberón MAInero, Miguel, "Personalidad", Diccionario jurídico mexicano, México, UNAM, t. VII, P-Reo, 1984.

TORRES LóPEZ, Erasmo Enrique, "El registro civil en el norte de México", El Diario de Coahuila, 1 de agosto de 2019.

TORRES, Luis Fernando, "El activismo judicial en la era neoconstitucional", Iuris Dicto, Revista del Colegio de Jurisprudencia de la Universidad San Francisco de Quito, año 13, vol. 15, 2013.

Urbiola Solís, Alejandra et. al., "Expresión y trabajo de los muxe' del istmo de Tehuantepec, en Juchitán de Zaragoza, México", Nova Scientia, Revista de Investigación de la Universidad de La Salle Bajío, León, México, vol. 9, núm. 19, 2017.

VÁZQUEZ AlONSO, Víctor, "Deferencia judicial hacia las agencias federales y deferencia hacia el legislador: la interpretación de la ley defectuosa y el principio democrático en la sentencia King v. Burwell", Revista General de Derecho Constitucional, Madrid, núm. 26, 2018. 
VON STRITZKY, Johannes, "El desarrollo de la protección jurídica de las personas homosexuales, bisexuales, transexuales e intersexuales (LGBT) en Alemania", Revista General de Derecho Constitucional, Madrid, num. 17, 2013.

Fecha de recepción: 15 de noviembre de 2019.

Fecha de aceptación: 12 de diciembre de 2020. 